\title{
Trend and Variability of China Precipitation in Spring and Summer: Linkage to Sea Surface Temperatures
}

\author{
FANGLIN YANG ${ }^{\mathrm{a}, *}$ and K.-M. LAU ${ }^{\mathrm{b}}$ \\ ${ }^{\text {a }}$ GEST/UMBC, Climate and Radiation Branch, NASA Goddard Space Flight Center, Greenbelt, \\ MD 20771, USA

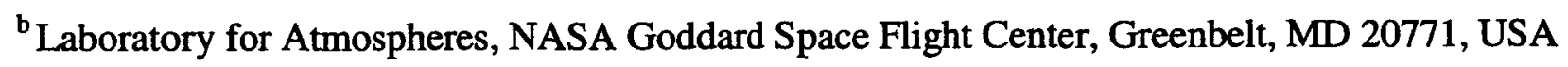

* Correspondence to: Dr. Fanglin Yang, Climate and Radiation Branch, NASA Goddard Space Flight Center, Code 913, Greenbelt, MD 20771, USA;

e-mail: fyang@climate.gsfc.nasa.gov 


\section{ABSTRACT}

Observational records in the past 50 years show an upward trend of boreal-summer precipitation over central eastern China and a downward trend over northern China. During boreal spring, the trend is upward over southeastern China and downward over central eastern China. This study explores the forcing mechanism of these trends in association with the global sea-surface temperature (SST) variations on the interannual and inter-decadal timescales.

Results based on Singular Value Decomposition analyses (SVD) show that the interannual variability of China precipitation in boreal spring and summer can be well defined by two centers of actions for each season, which are co-varying with two interannual modes of SSTs. The first SVD modes of precipitation in spring and summer, which are centered in southeastern China and northern China, respectively, are linked to an ENSO-like mode of SSTs. The second SVD modes of precipitation in both seasons are confined to central eastern China, and are primarily linked to SST variations over the warm pool and Indian Ocean. Features of the anomalous $850-\mathrm{hPa}$ winds and $700-\mathrm{hPa}$ geopotential height corresponding to these modes support a physical mechanism that explains the causal links between the modal variations of precipitation and SSTs.

On the decadal and longer timescale, similar causal links are found between the same modes of precipitation and SSTs, except for the case of springtime precipitation over central eastern China. For this case, while the interannual mode of precipitation is positively correlated with the interannual variations of SSTs over the warm pool and Indian Ocean; the inter-decadal mode is negatively correlated with a different SST mode, the North Pacific mode. The later is responsible for the observed downward trend of springtime precipitation over central eastern China. For all other cases, both the interannual and inter-decadal variations of precipitation can 
be explained by the same mode of SSTs. The upward trend of springtime precipitation over southeastern China and downward trend of summertime precipitation over northern China are attributable to the warming trend of the ENSO-like mode. The recent frequent summertime floods over central eastern China are linked to the warming trend of SSTs over the warm pool and Indian Ocean.

KEY WORDS: East Asian monsoon; precipitation; sea surface temperature; interannual and inter-decadal variability 


\section{INTRODUCTION}

Precipitation over China exhibits complex space and time structures. Large interannual variability causes local precipitation to fluctuate from year to year. Severe floods and droughts often occur in the same season of a year over different regions. For example, in the summer of 1997, southern China was flooded with excessive rainfall, while northern China faced one of the severest droughts on record (Huang et al., 2000; Lau and Weng, 2001). On the decadal and longer timescale, persistent dry and wet conditions have been observed over certain regions (e.g., Chang et al., 2000; Hu et al., 2003; Weng et al., 1999). During the second half of last century, northern China received abundant rainfall in the 1950's and suffered severe drought in the 1970's and 1980's. Over central eastern China, an upward trend of precipitation was observed in boreal summer and a downward trend in boreal spring. Over southern China, precipitation has been increasing in boreal spring and decreasing in boreal summer.

Precipitation over China has distinct seasonal characteristics, and is largely controlled by the monsoon circulation. In tradition, the time from mid-May to end of August has been defined as East Asian summer monsoon season (Tao and Chen, 1987). The heaviest rainfall often occurs in mid-June over the Yangtze River and Huaihe River Valleys. For this reason, earlier studies have focused almost exclusively on the June-July-August (JJA) season in the investigations of Asian precipitation variability and trends (Ding, 1992; Nitta and Hu, 1996; Lau and Yang, 1997; Chang et al., 2000; Wang et al., 2001; Lau and Weng, 2001; Gong and Ho, 2002; and many others). Little attention has been paid to the precipitation in the Mar-April-May (MAM) season. Our analysis (see Fig. 1) indicates, however, that over southern China (south of the Yangtze Rive), on average, precipitation in MAM and JJA each accounts for about $35 \%$ of the annual total. Over southeastern China, rainy season starts as early as March. Precipitation in March, 
April and May each accounts for about $10 \%$ of the annual total. Given the possibility that rainfall anomalies in MAM may presage those in JJA, we investigate in the present study the variability and trends of China precipitation in both the MAM and JJA seasons.

Precipitation over China is affected by both the internal dynamics of the monsoonal circulation and external forcing (Webster et al., 1998). A few major external forcing factors have been identified in previous studies to be influential on the variability of China precipitation, such as sea-surface temperatures (SST), Tibetan Plateau heating, Eurasian snow cover, and polar ice coverage. Among them, the influence of SSTs has been explored to the greatest extent. Most of the investigations have focused on the relation between China precipitation in boreal summer and the El Niño - Southern Oscillation (ENSO) events, mainly because of the overwhelming effects of ENSO on the climate system at the global scale. However, how ENSO events influence China summer precipitation is still not conclusive. Correlation between the eastern Pacific SST anomalies and China summer monsoon is weak, and not statistically significant (Chen et al., 1992). Wang et al. (2000) proposed a Pacific-East Asia teleconnection mechanism to explain the ENSO effect on East Asian climate. This mechanism emphasizes the importance of air-sea interaction over the Philippine Sea in modulating the strength and location of the western North Pacific anticyclones. In addition to the SSTs in the tropical central and eastern Pacific that are dominated by ENSO variability, SSTs over other oceanic regions, such as the Kuroshio currents, the western Pacific warm pool, the South China Sea and the Indian Ocean, have also been found to be influential on East Asian summer monsoon (e.g., Shen and Lau, 1995; Nitta and Hu, 1996; Huang and $\mathrm{Lu}, 1989$ ). Instead of focusing on SSTs in a particular region, we include in the present study the SSTs over the Indian Ocean and Pacific Ocean north of $30^{\circ} \mathrm{S}$. The covariance matrix built on the seasonal mean precipitation anomalies over eastern China and 
SST anomalies over the two oceanic basins is analyzed for each season in MAM and JJA using the Single Value Decomposition technique (Bretherton et al., 1992) to search for coupled patterns of precipitation and SSTs that are co-varying in time. This technique is capable of finding the SSTs over different oceanic regions that may possess collective effect on a certain mode of precipitation over China.

Weng et al. (1999) investigated the coupled variability of precipitation over China and global SSTs in boreal summer. They applied SVD to the unfiltered precipitation and SSTs and discovered a few dominant precipitation modes that are co-varying with SSTs at multiple timescales ranging from interannual to inter-decadal. In the present study we take a different approach by assuming that the modes of precipitation at the interannual and decadal timescales be not necessarily the same and that they might be forced by different modes of SSTs. This approach enables us to examine as well how the interannual and decadal components interplay. As will be shown later, at least for one mode of precipitation its variability at different timescales is linked to different modes of SSTs. In addition, the present study differs from Weng et al. (1999) in a few other aspects. We included both the MAM and JJA seasons and utilized different observational datasets. Considering the scarcity and quality of observations over western China, our investigation is limited to eastern China (east of $105^{\circ} \mathrm{E}$ ) instead of the entire country.

The purpose of the present study is to document the variability of China precipitation in boreal spring and summer, and its links to the variations of global SSTs at different oceanic regions and at different timescales. The possibility that the observed trends of China precipitation in the past 50 years were forced by inter-decadal SST variations is explored. For this purpose, we analyze first the basic features of the observed precipitation over East China 
(section 2) and the coupled modes of precipitation and SSTs at the interannual timescale (section 3). Attempts are made in section 4 to connect these modes with anomalous large-scale circulation and height field. Section 5 investigates the trends and decadal variability of the observed precipitation, and their possible links to the decadal variations of SSTs. The last section summarizes our findings and discusses issues that call for further investigation.

\section{OBSERVED TRENDS AND VARIABILITY}

This section documents basic features of the observed precipitation over China and global SSTs. The analysis is based on the New et al. (2000) precipitation and the NOAA Extended Reconstructed SSTs. The former has a resolution of $0.5 \times 0.5$ degrees and covers the time from 1901 to 1998 . The SST dataset was provided by the NOAA-CIRES Climate Diagnostics Center, Boulder, Colorado, USA, from their web site at http://www.cdc.noaa.govl. It has a resolution of $2 \times 2$ degrees and covers the time from 1854 to the present. We focused our investigation; on the period from 1951 to 1998 to take advantage of the better quality of data after 1950 and the availability of the NCEP/NCAR Reanalysis (Kalnay et al., 1996) after 1948. We have extended the analyses, where data permit, back to 1901, and also repeated the investigation for the 195198 period using another independent land precipitation product (Chen et al., 2002). We came to qualitatively the same conclusion.

Fig. 1 depicts the 1951-98 averaged seasonal mean precipitation for the MAM and JJA seasons, and the percentages of seasonal mean precipitation relative to the annual total. In MAM, heavy precipitation is confined to the south of the Yangtze River and concentrated over the southeast, reaching up to $7.0 \mathrm{~mm} /$ day. In JJA, precipitation band extends to northern China, with the rates decreasing gradually from south to north. Over southeastern China, precipitation in 
MAM and JJA each accounts for about $35 \%$ of the annual total. Over central eastern China along the Yangtze Rive and Huaihe River valleys, precipitation in MAM accounts for about $20 \sim 30 \%$ of the annual total, and in JJA about $40 \sim 50 \%$. Over northern China, precipitation is concentrated in the JJA season, accounting for more than $60 \%$ of the annual total. Previous studies have focused primarily on the summertime precipitation (e.g., Huang and Wu, 1989; Weng et al., 1999; Chang et al., 2000; Lau and Weng, 2001; Wang et al., 2001). Fig. 1 reveals that over southeastern and central eastern China precipitation in MAM is as important as that in JJA. This fact motivated us to examine precipitation in both the seasons.

The trends of precipitation in JJA over central and northern China in recent decades have been documented in a few earlier studies (e.g., Weng et al., 1999; Chang et al., 2000), and have drawn different speculations on its causes (e.g., Menon et al., 2002; Gong and Ho, 2002). In the present study precipitation trends are detected in both the JJA and MAM seasons. Fig. 2 displays the differences between the means of precipitation averaged for the 1975-98 period and the 1951-74 period in each season. Consistent with earlier findings, in JJA precipitation exhibits an upward trend over central eastern China and a downward trend over northern China. On contrast, in MAM, an upward trend over southeastern China and a downward trend over central eastern China are detected. Interestingly, the MAM and JJA trends are almost opposite to each other in geographical locations. To illustrate further how precipitation over different regions has varied from year to year, we divided East China into three sections, i.e., southern China $\left[110^{\circ} \mathrm{E}-122^{\circ} \mathrm{E}\right.$; $\left.21^{\circ} \mathrm{N}-28^{\circ} \mathrm{N}\right]$, central China $\left[110^{\circ} \mathrm{E}-122^{\circ} \mathrm{E} ; 28^{\circ} \mathrm{N}-33^{\circ} \mathrm{N}\right]$ and northern China $\left[110^{\circ} \mathrm{E}-122^{\circ} \mathrm{E}\right.$; $\left.33^{\circ} \mathrm{N}-40^{\circ} \mathrm{N}\right]$. Mean precipitation anomalies over each section were computed for the years from 1951 through 1998 for each season. The anomaly at each grid point was predefined as the departure from the 1951-98 seasonal mean. Fig. 3 shows the time evolutions of the means over 
southern China and central China for MAM and the means over central China and northern China for JJA. A 7-year running mean is also added to each bar graph to illustrate decadal variations and long-term trends. The time series for all sections and in both seasons show large interannual and decadal variations. A switch of the anomaly sign around the mid 1970's is prominent for all cases. In MAM, southern China was very dry in the 1960's and wet in the 1980's. In JJA, central China experienced frequent droughts in the 1950's and frequent floods in the late 1990's, and a general upward trend of precipitation starting in the 1960's. The variation indicates an inter-decadal variation. For northern China in JJA, it was rather wet in the 1950's and early 1960 's, and extremely dry in the 1980 's. In late 1990 's, the drought situation over northern China was somewhat alleviated, though 1997 summer was the driest in the record. Lau and Weng (2001) found that the 1997 drought over northern China and the 1998 flood over central China were triggered by the $1997-98$ El Niño event.

The trend and variability of global SSTs have been documented in detail in many studies (e.g., Zhang et al., 1997; Xue et al., 2003). For illustration purpose we present in Fig.4 the differences of seasonal mean SSTs between the 1975-89 and 1951-74 periods in MAM and JJA, respectively, over the domain $\left[30^{\circ} \mathrm{E}-60^{\circ} \mathrm{W} ; 30^{\circ} \mathrm{S}-60^{\circ} \mathrm{N}\right]$. For both the seasons, the SST patterns are similar, indicting upward trends over the central and eastern tropical Pacific and tropical Indian Ocean, and downward trends over the central to western North Pacific. Are the trends of China precipitation linked to the trends of global SSTs? Are the relations between China precipitation and global SSTs on the interannual timescale different from that on the decadal timescale? These questions are addressed in the following sections. 


\section{COHERENT MODES OF PRECIPITATION AND SSTS ON INTERANNUAL TIMESCALE}

Singular Value Decomposition (SVD) is used in this section to identify coupled modes of variability between precipitation and SSTs. SVD (Bretherton et al., 1992) decomposes the crosscovariance matrix of two data fields and identifies the pairs of spatial patterns that explain the mean-squared temporal covariance between the two fields. It can explain the maximum possible fraction of the cumulative squared covariance with fewer leading modes than any other tool that is capable of isolating coupled modes of variability between the time series of two fields. It should be point out that, due to its limitations, the SVD, under certain circumstances, may produce paired patterns of no physical meaning (Newman and Sardeshmukh, 1995; Cherry, 1997; $\mathrm{Hu}, 1997$ ). Cherry (1997) suggests that, prior to the use of SVD, one should apply empiricalorthogonal-function (EOF) analysis to each field to test if the two sets of expansion coefficients from EOF analysis are strongly correlated and the patterns are geophysically relevant. We had carried out EOF analyses on the precipitation and SST fields and assured such conditions were met. Newman and Sardeshmukh (1995) suggest, from a different perspective, that SVD modes are physically meaningful only if they explain significant portions of the variance of their respective fields. The percent variances explained by the first two leading modes from our SVD analyses (see Tables 1 and 2) are by-and-large significant. Thus, it is appropriate and advantageous to utilize the SVD technique in this study.

Weng et al. (1999) and Lau and Weng (2001) investigated the coupled modes between China precipitation and global SSTs in boreal summer. They applied SVD to the observed precipitation from 1954 through 1998 at all meteorological stations in China and a global SST dataset that is different from what we used here. Considering the scarcity of observations over 
western China, we focused our investigation on eastern China, but included the spring season. In addition, a digital filter (Duchon, 1979) with a cutoff period of seven years was utilized to extract the high and low-frequency components from the observed seasonal mean anomalies. The SVD analysis was applied to the high-frequency component. Consequently, the coupled modes of precipitation and SSTs identified by the SVD analysis explain only the variability on the interannual timescale. This approach enables us to examine how the interannual and decadal components interplay.

We performed SVD analyses using the 7-year high-frequency-pass filtered datasets of precipitation over East China $\left[105^{\circ} \mathrm{E}-122^{\circ} \mathrm{E}, 21^{\circ} \mathrm{N}-42^{\circ} \mathrm{N}\right]$ and SSTs in the Pacific and Indian Ocean north of $30^{\circ}$ S, for the MAM and JJA seasons and for the years from 1951 through 1998. The percent variances of the individual SST and precipitation fields and the fractional variance of the SST-precipitation co-varying matrix explained by the first two leading SVD modes are listed in Table 1, together with the correlations between the principle components (PC)" of the SST and precipitation modes. The first two leading modes of SST and precipitation for botth the MAM and JJA seasons are presented in Fig. 5 as homogeneous correlation maps. The SST (precipitation) homogeneous correlation map depicts the correlation between the filtered SST (precipitation) anomaly at each grid point and the leading-mode PC of SSTs (precipitation). At each grid point, the square of the correlation measures the percent variance explained by the corresponding mode.

In MAM, the first SST mode (Fig. 5a) is a typical ENSO-like mode, with positive anomalies in the central and eastern tropical Pacific and Indian Ocean, and a horse-shoe shape of negative anomalies in the tropical western Pacific. The co-varying precipitation mode (Fig. 5e) explains more than $60 \%$ of local precipitation variance over southeastern China. The first SVD 
mode explains $31 \%$ SST variance, $27 \%$ precipitation variance and $27 \%$ fractional variance of the SST-precipitation co-varying matrix. The PCs of SST and precipitation are positive correlated at 0.57. This implies that in years when the central and eastern tropical Pacific and Indian Ocean are abnormally warm in MAM, southeastern China tends to have more precipitation. The second SST mode in MAM (Fig. 5b) reflects SST variations over the warm pool and Indian Ocean and, to a lesser degree, over eastern North Pacific. Precipitation over central eastern China is positively correlated to the PC of SSTs (Fig. 5f). The second SVD mode explains 11\% SST variance, $15 \%$ precipitation variance and $14 \%$ fractional variance. The correlation between the PCs of SST and precipitation is 0.64. In non-ENSO years when the western tropical Pacific and Indian Ocean is abnormally warm (cold) in MAM, central eastern China tends to have more (less) precipitation.

In JJA, the first SST mode depicts also as a typical ENSO-like mode (Fig. 5c), and explains $43 \%$ of its own variance. Precipitation over northern China is highly correlated with this mode of SSTs. The correlation between the PCs of precipitation and SSTs reaches -0.77 . Such a negative relation between the tropical central and eastern Pacific SSTs and the northern China precipitation has been confirmed by both atmospheric general circulation model (GCM) simulations and observational data analyses (e.g., Wang and Li, 1990; Ju and Slingo, 1995; Weng et al., 1999; Chang et al., 2000). In years when SSTs in the central and eastern tropical Pacific are abnormally warm, East Asian monsoon circulation tends to be weak and the monsoon onset is usually delayed. This results in less precipitation in late summer over northern China. The second SVD modes of SSTs and precipitation in JJA (Fig. 5d and 5h) show that over central eastern China the interannual variation of precipitation is correlated with a north-south dipole mode of SST anomalies over the western North Pacific, the tropical Indian Ocean and the warm 
pool. This SVD mode explains $7 \%$ SST variance, $17 \%$ precipitation variance and $13 \%$ fractional variance. The PCs of precipitation and SST are positively correlated at 0.76 . In years when SSTs over the warm pool and northern Indian Ocean are abnormally warm and SSTs over the western North Pacific abnormally cold, precipitation over the central eastern China tends to be heavier than usual.

\section{ANOMALOUS WINDS AND HEIGHT}

In section 3 certain causal links are identified between the principle modes of precipitation over East China and the modal variations of global SSTs. In this section we investigate the characteristics of atmospheric circulation corresponding to these modes. The data used are the NCEP/NCAR reanalysis from 1951 through 1998 (Kalnay et al., 1996): We analyzed seasonal-mean zonal and meridional winds at $850 \mathrm{hPa}$ and geopotential height at 700 $\mathrm{hPa}$.

To be consistent with the SVD analysis that deal with only the interannual variability of precipitation and SSTs, all wind and height data were high-passed with a filter (Duchon, 1979) to truncate off the low-frequency components with periods longer than seven years. Then, the filtered winds and height at each grid points are regressed against the leading PCs of precipitation and SST, respectively. The regressions are shown in Fig. 6 as anomalous wind vectors at $850 \mathrm{hPa}$ and anomalous geopotential height at $700 \mathrm{hPa}$, with respect to one standard deviation of each PC. For both seasons and for all modes, the regressions to the PCs of precipitation resemble those to the PCs of SSTs in terms of pattern distribution since the PCs of precipitation and SSTs are highly correlated (see Table 1). For each PC, we also computed the composites of anomalous winds and height for extreme events with the PC greater or smaller 
than one standard deviation (not shown). The resulting composites of wind and height anomalies are in agreement with those derived from the regression analyses.

In MAM, the regressions to the first-mode PC of SSTs (Fig. 6a) and precipitation (Fig.6e) both show positive height anomalies in the subtropics and negative anomalies in the mid-latitude western Pacific. Anomalous geostrophic flow enhances the climate-mean southeast winds over southeastern China. In combination with Figs. 5a and 5e a picture emerges of how the anomalous SSTs influence the springtime precipitation over southern China. In years when the SSTs in the central and eastern tropical Pacific and Indian Ocean are above normal, SSTs in the western tropical Pacific are usually below normal (Fig.5a). The western Pacific subtropical high tends to remain in the south. As a result, abnormally strong southeast winds along the edge of the subtropical high bring more warm and moist air, and hence more precipitation over southeastern China. The opposite is true for the negative phase of the SST mode.

The regressions to the second-mode PC of SSTs (Fig. 6b) and precipitation (Fig.6f) in MAM indicate that when above normal SSTs exist over the warm pool and northern Indian Ocean (Fig.5b), the western Pacific subtropical high is abnormally strong and is shifted northward. The height anomalies over northern Eurasia are negative. Stronger south and southeast flows along the west edge of the subtropical high bring abundant warm and moist air to central eastern China. A convergence zone forms, and above normal precipitation occurs over the downstream of the Yangtze Rive valley (Fig. 5f).

In JJA, precipitation over northern China is negatively correlated with the ENSO-like SST mode, hence a negative correlation between the first-mode PCs (Table 1). For clarity, we have reserved the sign of the PC for precipitation for regression analysis. The results (Figs. 6c and $6 \mathrm{~g}$ ) indicate that in years when the SSTs are abnormally warm in the central and eastern 
tropical Pacific and cold in the western tropical Pacific, a typical ENSO-like mode, the western Pacific subtropical high tends to retreat to the east. Anomalous low-level southwest flow weakens the normal southeast monsoon winds along the edge of the sub-tropical high over central and northern China in the summer months. Moreover, an anomalous low occurs over northeastern China. The anomalous cyclonic flow over northern China brings dry and cold air to northeastern China. As a result, the monsoon precipitation over northern China is suppressed.

The regressions to the PCs of the second modes of precipitation and SSTs for the JJA season (Figs. 6d and 6h) show that in years when the SSTs are above normal in the northern Indian Ocean and the warm pool and below normal in the mid-latitude western Pacific (Fig. 5d), a strong north-south dipole of height anomalies forms, with negative to the north and positive to the south divided at about $30^{\circ} \mathrm{N}$. From the south, anomalous southeast flow enhances the climate-mean southeast monsoon winds and brings more warm and moist air to the central eastern China. From the north, anomalous south flow weakens the climate-mean monsoon winds and brings down cold and dry air. The two branches of anomalous flow converge over central eastern China and produce above normal precipitation.

In this section the dynamical links between the anomalous SSTs and China precipitation are explored through regression analyses. The SSTs over the warm pool and northern Indian Ocean play a key role in modulating the strength and displacement of the western Pacific subtropical highs. The corresponding anomalous monsoonal flow affects the direction and strength of the transport of water vapor to East China, and consequently affects the interannual variability of precipitation over this region.

\section{DECADAL VARIATIONS AND TRENDS}


So far we have analyzed the interannual variability of China precipitation in boreal spring and summer and its associated monsoon circulation, and found that variations of China precipitation consist of a few well-defined modes that are linked to SSTs in different oceanic regions. On the longer timescale, both the observed precipitation and SSTs exhibit decadal variations and long-term trends (Figs. 2-4). Weng et al. (1999) applied SVD analyses to unfiltered precipitation and SSTs to document the coupled modes of SST and precipitation in JJA. They did not separate the interannual variations from the inter-decadal components. In this section we address the following question. Are the modes of China precipitation on the decadal timescale different from that at the interannual timescale? Previous studies (e.g., Trenberth and Hurrell, 1994; Zhang et al., 1997) have showed that the dominant SST modes, such as the ENSO and North Pacific mode, consist of variations with period ranging from seasons to decades. Can the observed decadal variations and trends of China precipitation be explained by the decadal variations of SSTs?

We performed first matrix operations by multiplying the observed unfiltered seasonal mean precipitation and SST anomalies with the respective leading SVD modes of precipitation and SSTs shown in Fig. 5 for each season. The resulting time series, referred to as projections to the SVD modes, illustrates to what degree the observed anomaly in a given year is associated with the dominant interannual SVD modes. The projections of SST anomalies to the first two leading SST modes are shown in Fig. 7 as bars for each mode and each season. The lines in Fig. 7 are 7-year running means of the projections. On the interannual timescale, the projections resemble the corresponding PCs of the leading SST modes in both MAM and JJA (not shown). The first projection (PJ1_SST) in both MAM and JJA captures the major cold and warm events in the tropical Pacific and Indian Ocean. The second projection (PJ2_SST) reflects primarily SST 
variations over the warm pool and Indian Ocean. However, unlike the PCs, these projections, except for PJ2_SST in MAM, all demonstrate a distinct upward trend in the 48-year period from 1951 through 1998, with the turning point locked at the mid 1970's. The trends indicate a basinwide warming of SSTs in the tropics.

The projections of precipitation anomalies to the first two leading modes of precipitation are presented in Fig. 8. On the interannual timescale these projections also resemble the corresponding PCs of precipitation (not shown). Unlike the PCs, inter-decadal variations and trends are superimposed on the interannual variations of the projections. PJ1 in MAM and PJ2 in JJA show upward trends of precipitation and PJ2 in MAM and PJ1 in JJA show downward trends.

In comparison with the area-mean anomalies of precipitation shown in Fig. 3 , the projections of precipitation (Fig. 8) exhibit some interesting features. In MAM, PJ1 matches the "south China" mean and PJ2 matches the "central China" mean. In JJA, PJ1 matches the "north China" mean, and PJ2 the "central China" mean. These projections and area means match each other in the sense that they possess not only similar interannual variations but also have almost identical inter-decadal variations for the 48-year period. Referring to the leading modes of precipitation shown in Figs. 5, we propose that the observed precipitation trends over the different sections of East China and in different seasons during the 1951-98 period are forced by the long-term variations in the strength and polarization of those dominant interannual precipitation modes. Given the fact that the interannual modes of precipitation are co-varying with the dominant interannual modes of SSTs identified by SVD in section 3, and that those interannual modes of SSTs also posses decadal variations and trends (Fig. 7), we propose further that the observed long-term variations of precipitation over East China are forced by the decadal 
variations of the dominant interannual SST modes. The more frequent floods over southeastern China in MAM and severe droughts over northern China in JJA in recent decades are forced by the upward trend of SSTs associated with the ENSO-like mode (Figs. 5a and 5c). The recent frequent flooding events in JJA over central eastern China are linked to the trend of the second mode of SSTs, which reflects primarily the SST variations over northern Indian Ocean and the warm pool. The case for the upward trend of precipitation over central eastern China in MAM is an exception, for which the explanation follows.

For the precipitation over central eastern China in MAM, the SVD analysis in section 3 indicates that on the interannual timescale, precipitation is positively correlated with the SSTs over the Indian Ocean and the warm pool (Fig. 5b). While in MAM the projection of precipitation anomalies to the second mode of precipitation (Fig. 8b) shows a downward trend that resembles the evolution of the observed "central China" precipitation (Fig. 3b), the projection of SST anomalies in MAM to the second SST mode (Fig. 7b) shows actually a weak upward trend. These seemly contradictory relations suggest that over central eastern China the decadal variation of precipitation in MAM may not be associated with the interannual mode identified by the SVD analysis using the high-pass filtered data.

To test this possibility, we separate first each time series of the area-mean precipitation anomalies shown in Fig. 3 into interannual and decadal components by applying a digital filter with a 7-year cutoff period. Then we correlated the interannual and the decadal time series with the corresponding 7-year high- and low-pass-filtered SSTs, respectively, at each oceanic grid point. The computed anomalous correlations are presented in Fig.9 for the cases of "south China" and "central China" in MAM and "central China" and "north China" in JJA. The contrast between the high-pass and low-pass correlation maps for the "central China" case in 
MAM is distinctly different from that for the other three cases. For the cases of "south China" in MAM and "central China" and "north China" in JJA, the pair of the high-pass and low-pass correlation maps resemble each other, and are both similar in terms of pattern distributions to the corresponding SST modes in Fig. 5. The result reinforces the notion that, for these cases, the interannual and decadal variations of precipitation over each region and for each season are controlled by a single precipitation mode, which is linked to the same mode of SSTs as suggested by Weng et al. (1999). However, for the "central China" case in MAM, the high-pass correlation map (Fig. 9b) is totally different from the low-pass correlation map (Fig. 9f). The former resembles the interannual SST mode in Fig.5b, and the later resembles the long-term SST trend in Fig. 4a. Therefore, in MAM over central eastern China there are two precipitation modes operating at different timescales. The interannual mode is forced by and positively correlated with the interannual modes of SSTs over Indian Ocean and the warm pool (Fig. 5b). The decadal mode is forced by and negatively correlated with the basin-wide decadal variations of SSTs in the entire Indian and Pacific oceans (Fig. 9f). The observed downward trend of precipitation over central eastern China in MAM (Fig. 3b) is linked to the basin-wide warming trend of SSTs. (Fig.4a).

We test further the above hypothesis by repeating the SVD analysis described in section 3 with unfiltered seasonal mean precipitation and SST anomalies. The resulting modes are presented in Fig.10 and the percent variances explained by each mode and the correlations between the PCs are listed in Table 2. For JJA, the two leading modes of SSTs (Figs. 10c and 10d) and precipitation (Figs. 10g and 10h) are almost identical to those shown in Fig. 5. The resulting PCs (Fig. 11c and 11d) are similar to the PCs corresponding to Fig. 5 (not shown) in terms of interannual variability, but possess obvious inter-decadal variations and trends, which 
match the projections in JJA shown in Fig. 7 for SSTs and Fig. 8 for precipitation and the observed precipitation trends in Fig. $3 \mathrm{c}$ and $3 \mathrm{~d}$. Similar relations can be accounted for the first SVD modes of precipitation and SSTs for MAM (Figs. 10a and 10e). For the second SST mode in MAM (Fig. 10b), however, it is different from the interannual mode derived from the highpass filtered data (Fig. 5b). This SST mode reflects SST variations primarily in North Pacific. The PCs of SSTs and precipitation are negatively correlated at -0.61 (Fig. 11b). The PC of SSTs depicts a general upward trend, and the PC of precipitation shows a downward trend. This analysis confirms further that the forcing mechanism for the observed precipitation trend over central eastern China in MAM is different from the one for other cases. There are two different modes of SSTs operating at different timescales that control the precipitation variability over central eastern China in MAM.

\section{SUMMARY AND DISCUSSION \\ a. Summary}

In this study we documented the variability of China precipitation in boreal spring and summer and its links to global SSTs. Starting from the assumption that the modes of precipitation at the interannual and decadal timescales be not necessarily the same and that they might be associated with different modes of SSTs, we applied first SVD analysis to the highfrequency-pass filtered precipitation and SST anomalies to build the coupled modes of precipitation and SSTs on the interannual timescale. Results show that a large percent of the East China precipitation variance at the interannual timescale can be explained by two centers of actions for each season, which are co-varying with two interannual modes of SSTs. The leading SVD modes of precipitation in spring and summer, which are centered in southeastern China and 
northern China, respectively, are both linked to an ENSO-like mode of SSTs. In years when the central and eastern tropical Pacific and Indian Ocean are abnormally warm, precipitation tends to be above normal over southeastern China in MAM and below normal over northern China in JJA. The second SVD modes in both seasons reflect the interannual variability of precipitation over central eastern China, and are linked primarily to SST variations over the warm pool and Indian Ocean. In years when SSTs over these regions are abnormally warm, central eastern China tends to have more precipitation in both seasons. Further analyses of anomalous $850-\mathrm{hPa}$ winds and 700-hPa geopotential heights corresponding to these modes support a physical mechanism that explains the causal links between the modal variations of precipitation and SSTs.

Results based on projection, point correlation and SVD using unfiltered datasets show that, by and large, the coupled modes of precipitation and SSTs at the interannual timescale identified using filtered data operate also on the decadal timescale. Hence, the interannual and inter-decadal variations of precipitation can be explained by the same mode of SSTs. The upward trend of springtime precipitation over southeastern China and downward trend of summertime precipitation over northern China are linked to the warming trend of the ENSO-like SST mode. The recent frequent summertime floods over central eastern China are linked to the warming trend of SSTs over the warm pool and Indian Ocean. The exceptional case is for the springtime precipitation over central eastern China. For this case, while the interannual mode of precipitation positively correlates with SSTs over the warm pool and Indian Ocean; the interdecadal mode is negatively correlated with a different SST mode, the North Pacific mode. The later is responsible for the observed downward trend of springtime precipitation over central eastern China.

\section{b. Discussion}


The present study investigated only the contributions of SSTs to the observed trends and variability of China precipitation. Not all the variances of precipitation can be explained by SSTs. It is possible that other factors such as snow cover and polar ice concentration also play a role. A recent study by Menon et al. (2002) further suggests that the observed trends of China precipitation in recent decades are forced by the increase of black carbon emissions over South and East Asia.

The links between precipitation and SSTs identified in the present study do not evince necessarily a cause-and-effect relation. On the interannual time scale, SSTs over the warm pool and South China Sea are often influenced by strong anomalous monsoon circulation. Air-sea interaction can modulate the local SSTs (Wang et al., 2003). The monsoon-ENSO, relation is far more complicated than what we have attempted to address here. Anomalous monsoon circulation can affect the evolution or even trigger ENSO events. Barnett (1984) noted that on the interannual timescale the Asian monsoon and ENSO is strongly coupled through the propagation of anomalous atmospheric circulation from Indian to the Pacific sector. Shen and Lau (1995) found a strong biennial signal in the correlations between East Asian summer monsoon and the tropical SSTs. The present study suggests that precipitation over central eastern China is strongly coupled with SSTs over the western tropical Pacific and Indian Ocean. SST anomalies over these regions, in a certain degree, are related to ENSO, but also stand alone. We examined further the PCs corresponding to Fig.5 for extreme events, and found that in El Niño (La Niña) years precipitation is almost always above (below) normal over southeastern China in MAM and below (above) normal over northern China in JJA. However, ENSO events and extreme precipitation seasons do not match in all years. The effect of ENSO on precipitation over central eastern China is far less conclusive. 
For the changes in decadal and longer timescales, previous studies (e.g., Kinter et al., 2002; Wang, 2001) attributed the observed trends of China precipitation to the regime shift of the global climate system in the mid-1970's, although the mechanism of which is still not understood. It is possible that the observed trends in both precipitation and SSTs are merely a manifestation of the regime shift. There is also the possibility that global warming might has affected the precipitation patterns over China by directly changing the Asian monsoon dynamics and indirectly modifying the Eurasian snow cover and the polar ice concentration. By comparing observations with results from simulations of transient greenhouse warming by 16 coupled atmosphere-ocean GCMs, Hu et al. (2003) found that the observed long-term temperature variations over China in all seasons but summer may be associated with increases in greenhouse gas concentrations. Due to the large uncertainties among the GCMs in precipitation simulations they did not find a robust link between the precipitation variations and global warming. The present study may provide a working hypothesis for further investigations to better understand the variability and trends of China precipitation. 


\section{References}

Barnett TP. 1984. Interaction of the monsoon and Pacific trade wind system at interannual time scales. Part III: A partial anatomy of the Southern Oscillation. Monthly Weather Review 112: $2388-2400$.

Bretherton CS, Smith C, Wallace JM. 1992. An intercomparison of methods for finding coupled patterns in climate data. Journal of Climate 5: 541-560.

Cherry S. 1997. Some comments on singular value decomposition analysis. Journal of Climate 10: $1759-1761$.

Chang CP, Zhang Y, Li T. 2000. Interannual and interdecadal variations of the east Asian summer monsoon and tropical Pacific SSTs. Part I: Role of the subtropic ridge. Journal of Climate 13: $4310-4325$.

Chen L, Dong M, Shao Y. 1992. The characteristics of interannual variation on the East Asian monsoon. Journal of the Meteorological Society of Japan 70: 397-421.

Chen M, Xie P, Janowiak JE, Arkin PA. 2002. Global land precipitation: A 50-yr monthly analysis based on gauge observations. Journal of Hydrometeorology 3: 249-266.

Ding YH. 1992. Summer monsoon rainfalls in China. Journal of the Meteorological Society of Japan 70: 373-396.

Duchon CE. 1979. Lanczos filtering in one and two dimensions. Journal of Applied Meteorology 18: $1016-1022$.

Gong DY, Ho CH. 2002. Shift in the summer rainfall over the Yangtze River valley in the late 1970s. Geophysical Research Letter 29: 1436, doi:10.1029/2001GL014523.

Hu Q. 1997. On the uniqueness of the singular value decomposition in meteorological applications. Journal of Climate 10: 1762-1766. 
Hu ZZ, Yang S, Wu R. 2003. Long-term climate variations in China and global warming signals. Journal of Geophysical Research 108: 4614, doi:10.1029/2003JD003651.

Huang R, Lu L. 1989. Numerical simulation of the relationship between the anomaly of subtropical high in East Asia and the convective activities in the tropical western Pacific. Advances in Atmospheric Sciences 6: 202-214.

Huang R, Wu Y. 1989. The influence of ENSO on the summer climate change in China and its mechanism. Advances in Atmospheric Sciences 6: 21-32.

Huang R, Zhang R, Zhang Q. 2000. The $1997 / 98$ ENSO cycle and its impact on summer climate anomalies in East Asia. Advances in Atmospheric Sciences 17: 348-362.

Ju JH, Slingo J. 1995. The Asian summer monsoon and ENSO. Quarterly Journal of the Royal Meteorological Society 121: 1133-1168.

Kalnay E, and Co-authors. 1996. The NCEP/NCAR 40-year reanalysis project. Bulletin of the American Meteorological Society 77: 437-471.

Kinter III JL., Miyakoda K, Yang S. 2002. Recent change in the connection from the Asia monsoon to ENSO. Journal of Climate 15: 1203-1215.

Lau KM, Weng H. 2001. Coherent modes of global SST and summer rainfall over China: An assessment of the regional impacts of the 1997-98 El Niño. Journal of Climate 14: 12941308.

Lau KM, Yang S. 1997. Climatology and interannual variability of the Southeast Asian summer monsoon. Advances in Atmospheric Sciences 14: 141-162.

Menon S, Hansen J, Nazarenko L, Luo YF. 2002. Climate effects of black carbon aerosols in China and India. Science 297: 2250-2253. 
New M, Hulme M, Jones P. 2000. Representing twentieth-century space-time climate variability. Part II: development of 1901-96 monthly grids of terrestrial surface climate. Journal of Climate 13: 2217-2238.

Newman M, Sardeshmukh P. 1995. A caveat concerning singular value decomposition. Journal of Climate 8: 352-360.

Nitta T, Hu ZZ. 1996. Summer climate variability in China and its association with $500 \mathrm{hPa}$ height and tropical convection. Journal of the Meteorological Society of Japan 74: 425-445.

Shen S, Lau KM. 1995. Biennial oscillation associated with the East Asian summer monsoon and tropical sea surface temperature. Journal of the Meteorological Society of Japan 73: $105-124$.

Tao SY, Chen LX. 1987. A review of recent research of the East Asian summer monsoon in China. Monsoon Meteorology, Chang CP and Krishnamurti TN, Eds., Oxford University Press: 60-92.

Trenberth KE, Hurrell JW. 1994. Decadal atmosphere-ocean variations in the Pacific. Climate Dynamics 9: 303-319.

Wang HJ. 2001. The Weakening of the Asian monsoon circulation after the end of 1970's. Advances in Atmospheric Sciences 18: 376-386.

Wang B, Wu R, Lau KM. 2001. Interannual variability of the Asian summer monsoon: Contrasts between the Indian and the western North Pacific-east Asian monsoons. Journal of Climate 14: $4073-4090$.

Wang B, Wu R, Fu X. 2000. Pacific-East Asian teleconnection: How does ENSO affect East Asian climate. Journal of Climate 13: 1517-1536. 
Wang B, Wu R, Li T. 2003. Atmosphere-warm ocean interaction and its impacts on AsianAustralian monsoon variation. Journal of Climate 16: 1195-1211.

Wang WC, Li KR. 1990. Precipitation fluctuation over semiarid region in northern China and the relationship with El-Nino Southern Oscillation. Journal of Climate 3: 769-783.

Webster PJ., Magana VO, Palmer TN, Shukla J, Tomas RA, Yanai M, Yasunari T. 1998. Monsoons: Processes, predictability, and the prospects for prediction. Journal of Geophysical Research 103: 14451-14510.

Weng H, Lau KM, Xue Y. 1999. Multi-scale summer rainfall variability over China and its longterm link to global sea surface temperature variability. Journal of the Meteorological Society of Japan 77: 845-857.

Xue Y, Smith TM, Reynolds RW. 2003. Interdecadal changes of 30-yr SST normals during 1871-2000. Journal of Climate 16: 1601-1612.

Zhang Y, Wallace JM, Battisti DS. 1997. ENSO-like interdecadal variability: 1990-1993. Journal of Climate 10: 1004-1020. 
Table 1. Percent variances of SST, precipitation and the SST-precipitation co-varying matrix explained by the leading SVD modes, and the correlations between the principle components of SST and precipitation. Results are based on 7-year high-frequency-pass filtered data.

\begin{tabular}{lcccc} 
SST & $\begin{array}{c}\text { Precipitation } \\
\text { Variance }\end{array}$ & $\begin{array}{c}\text { SST-Precipitation } \\
\text { Co-Variance }\end{array}$ & $\begin{array}{c}\text { Correlation } \\
\text { (PC_sst, PC_precip) }\end{array}$ \\
\hline SVD 1 & $31 \%$ & MAM & $27 \%$ & 0.57 \\
SVD 2 & $11 \%$ & $27 \%$ & $14 \%$ & 0.64 \\
& & $15 \%$ & & -0.77 \\
SVD 1 & $43 \%$ & $10 \%$ & $24 \%$ & 0.76 \\
SVD 2 & $7 \%$ & $17 \%$ & $13 \%$ & \\
\hline
\end{tabular}


Table 2. Same as Table 1, except that the SVD analysis was performed using unfiltered data.

\begin{tabular}{ccccc} 
SST & $\begin{array}{c}\text { Precipitation } \\
\text { Variance }\end{array}$ & $\begin{array}{c}\text { SST-Precipitation } \\
\text { Co-Variance }\end{array}$ & $\begin{array}{c}\text { Correlation } \\
\text { (PC_sst, PC_precip) }\end{array}$ \\
\hline SVD 1 & $34 \%$ & MAM & $28 \%$ & 0.55 \\
SVD 2 & $7 \%$ & $25 \%$ & $11 \%$ & -0.61 \\
SVD 1 & $33 \%$ & $16 \%$ & & -0.66 \\
SVD 2 & $6 \%$ & $9 \%$ & $19 \%$ & 0.70 \\
\hline
\end{tabular}




\section{Figure Captions}

Figure1. Seasonal mean precipitation (mm/day) in (a) MAM and (b) JJA averaged for the 195198 period, and the percentage of seasonal mean precipitation relative to the annual total for (c) MAM and (d) JJA.

Figure 2. Differences of seasonal mean precipitation (mm/day) between the 1975-98 average and the 1951-1974 average for (a) MAM, and (b) JJA.

Figure 3. Regional and seasonal mean precipitation anomalies ( $\mathrm{mm} /$ day) shown as bars for (a) MAM over southern China, (b) MAM over central China, (c) JJA over central China and (d) JJA over northern China. The line in each panel shows the 7-year running means of the bars, and depicts the decadal variation of the regional mean precipitation. The regions are defined in the text. Precipitation anomalies are computed at each grid point before regional means are derived. The anomaly at each grid point is defined as the departure from the 1951-98 seasonal mean.

Figure 4. Same as Fig.2, except for SSTs.

Figure 5. First two leading SVD modes of SSTs (left panels) and precipitation (right panels) for MAM (upper four panels) and JJA (lower four panels). These modes are derived from 7-year high-frequency-pass filtered precipitation and SSTs, and are shown as homogeneous correlation maps. 
Figure 6. Regressions of $850-\mathrm{hPa}$ zonal and meridional winds and $700-\mathrm{hPa}$ geopotential height against the PCs of the SVD modes shown in Fig.5. Left panels are for the regressions against the PCs of SSTs, and right panels for those against the PCs of precipitation. The winds and height data are filtered to exclude variations with period longer than 7 years. The resulting anomalous winds $(\mathrm{m} / \mathrm{s})$ are shown in each panel as vectors, and anomalous geopotential height $(\mathrm{m})$ in colors. Note that for JJA the sign of rain_PC1 was reserved before regression because it is negatively correlated with SST_PC1.

Figure 7. Projections of the observed unfiltered SST anomalies in MAM and JJA to the SVD modes of SSTs as illustrated in Fig. 5. The projection is defined as a matrix product between each SVD mode and the seasonal mean unfiltered SST anomalies over the same domain given by SVD mode. The lines are 7-year running means of the projections.

Figure 8. Same as in Fig. 7, except for precipitation.

Figure 9. Correlations between high- and low-pass-filtered regional mean precipitation in Fig. 3 and the corresponding filtered SST anomalies. Left panels are for the 7-year high-pass filtered, and right panels for the 7-year low-pass filtered. See text for the details.

Figure 10. Same as Fig.5, except that the modes are derived from unfiltered SSTs and precipitation. 
Figure 11. Principle components (PCs) for the first two leading SVD modes derived from unfiltered SSTs and precipitation as shown in Fig.10. The PCs for the SST modes are solid bars, and those for the precipitation modes are hollowed bars. Each PC is normalized by its own standard deviation. The correlation between the pair of PCs in each panel is displayed. 
Precip, 1951-1998, Hadley
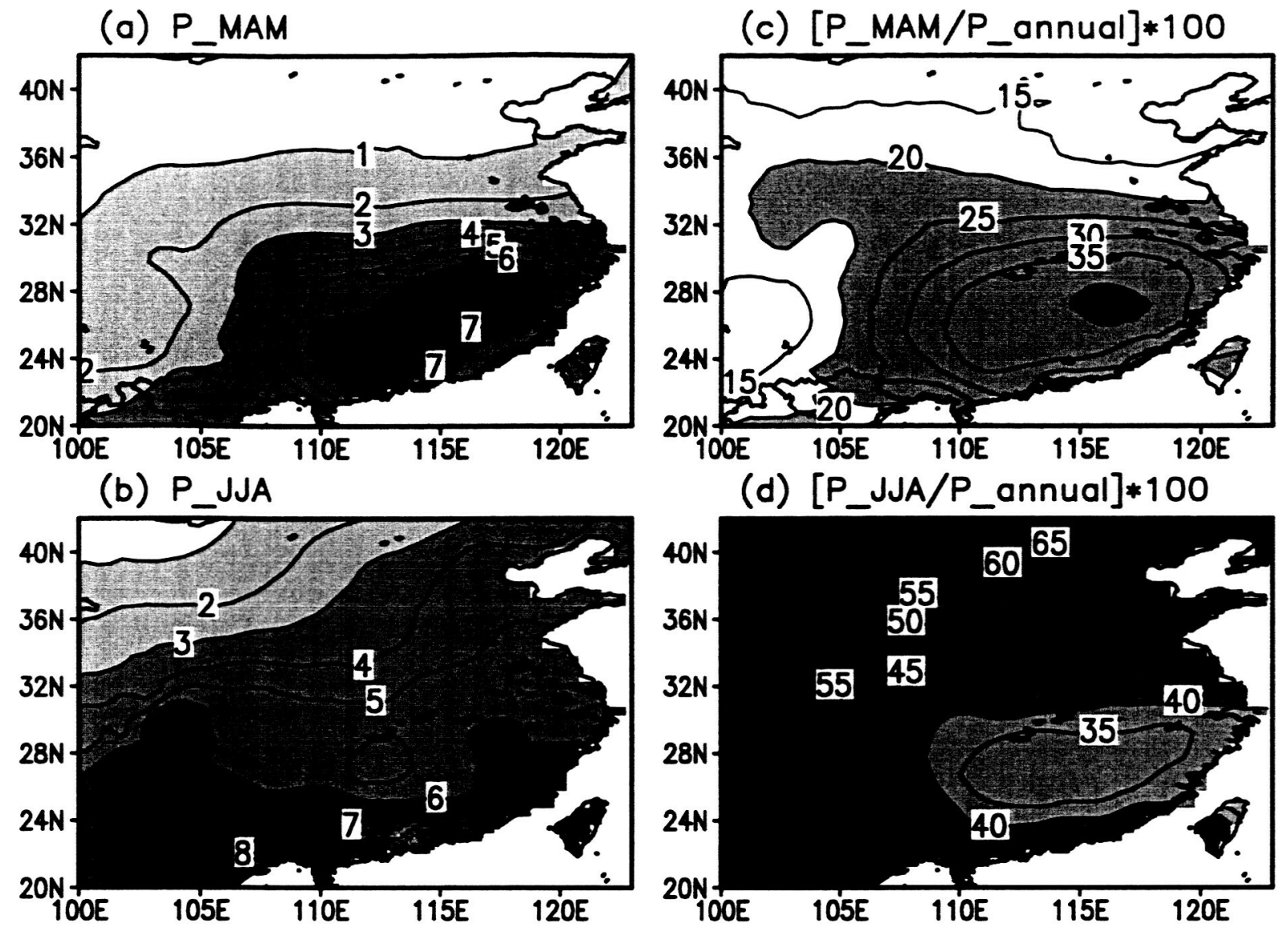
Hadley Precip Trend, $\mathrm{mm} /$ day

[1975-1998] - [1951-1974]

(a) MAM

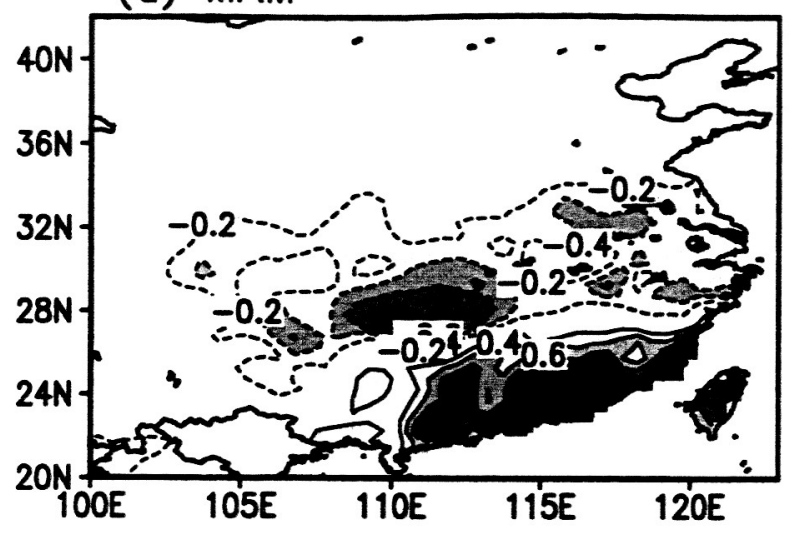

(b) JJA

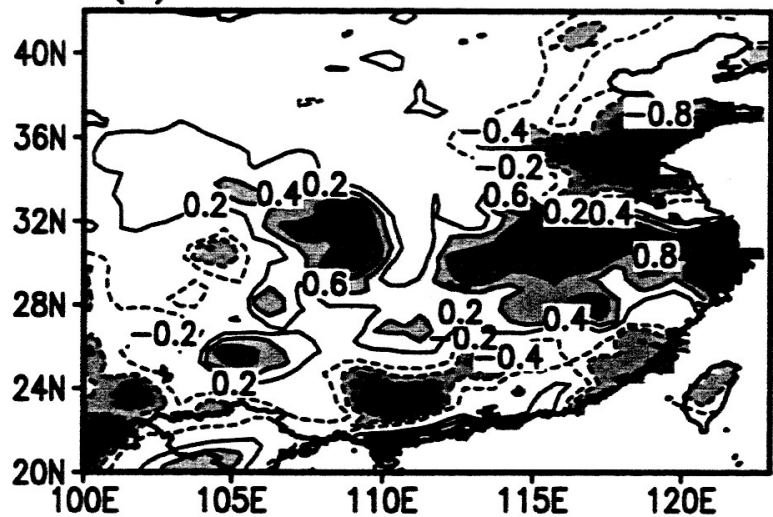

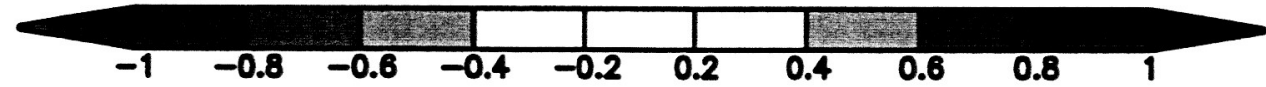


Hadley Precip Anomalies, mm/day, Base: 1951-1998 red Line: 7-year sliding avergae, [105E-122E]

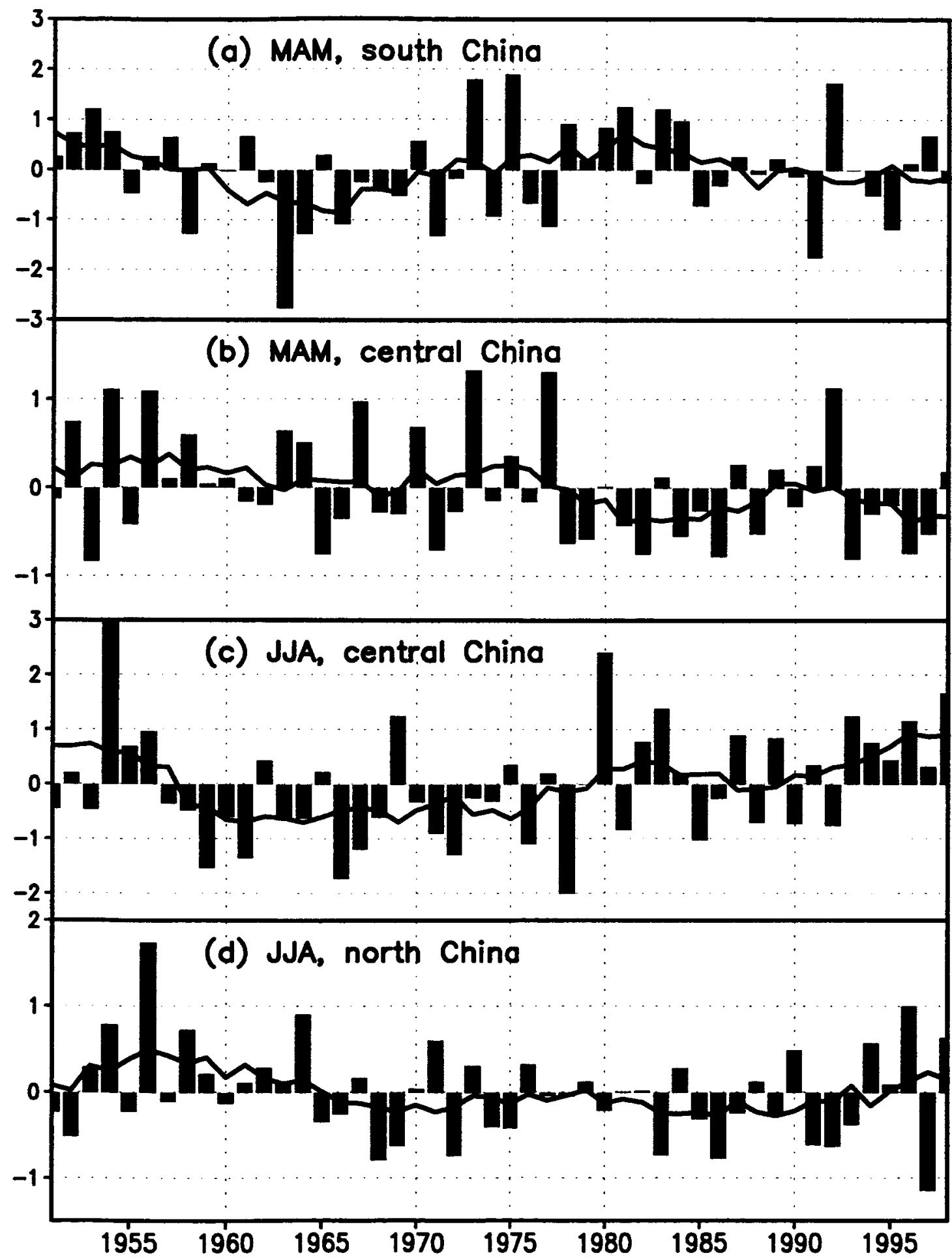




$$
\begin{gathered}
\text { NOAA ERSST Trend } \\
{[1975-1998]-[1951-1974]}
\end{gathered}
$$
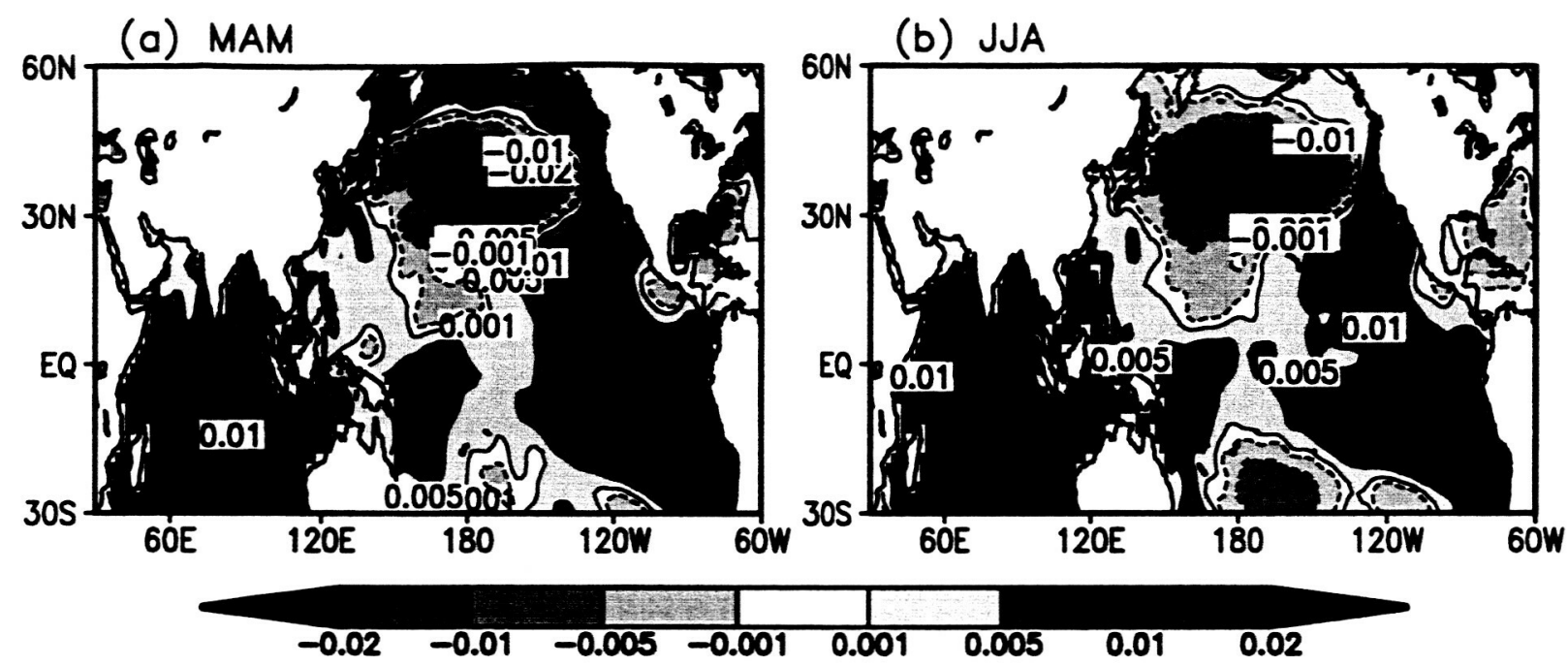
SVD: SST and Rainfail, 1951-98

7-year high-pass filtered data

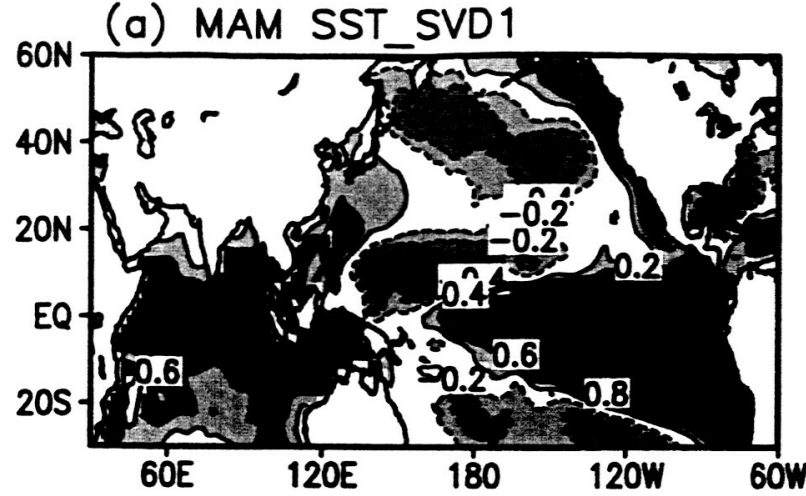

(e) MAM rain_SVD1

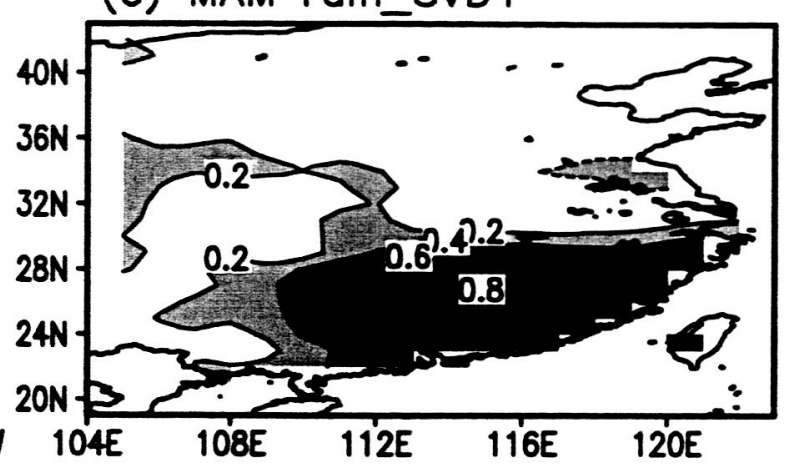

(b) MAM SST_SVD2

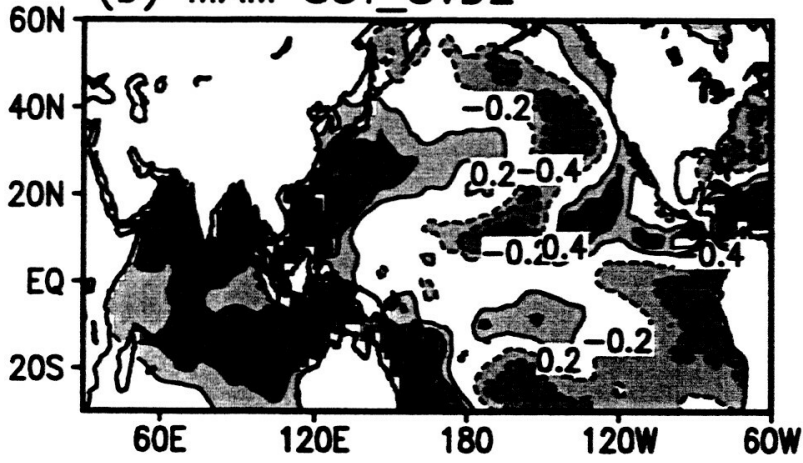

(f) MAM rain_SVD2

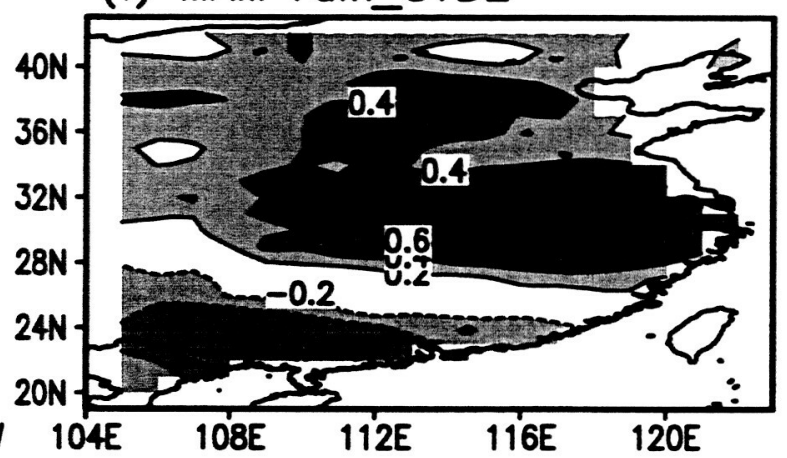

(c) JJA SST_SVD1

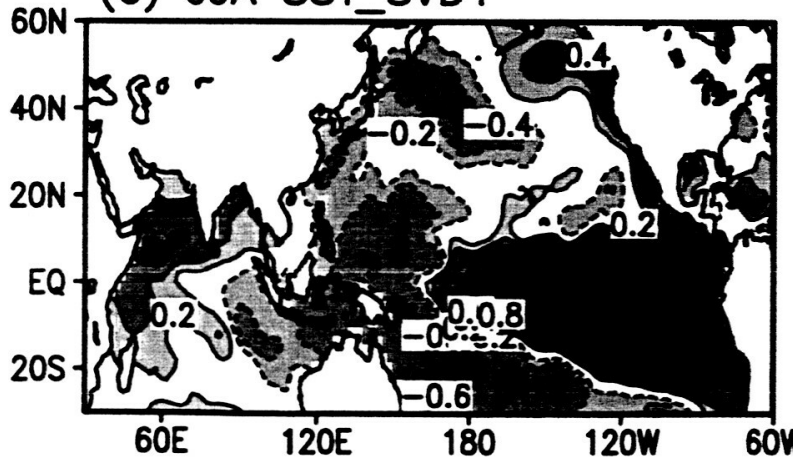

(g) JJA rain_SVD1

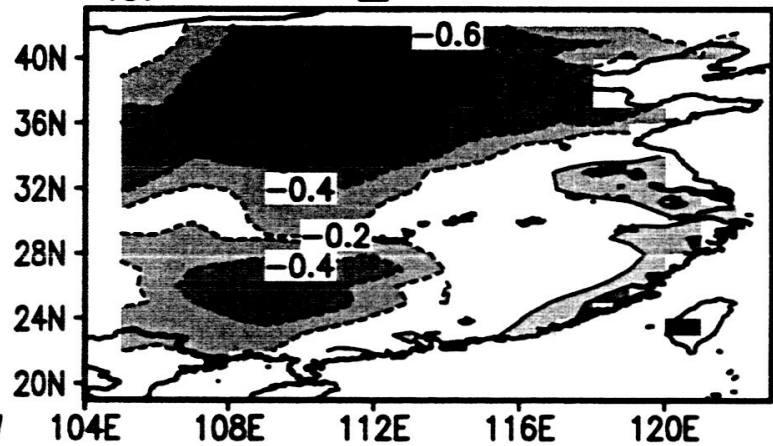

(d) JJA SST_SVD2

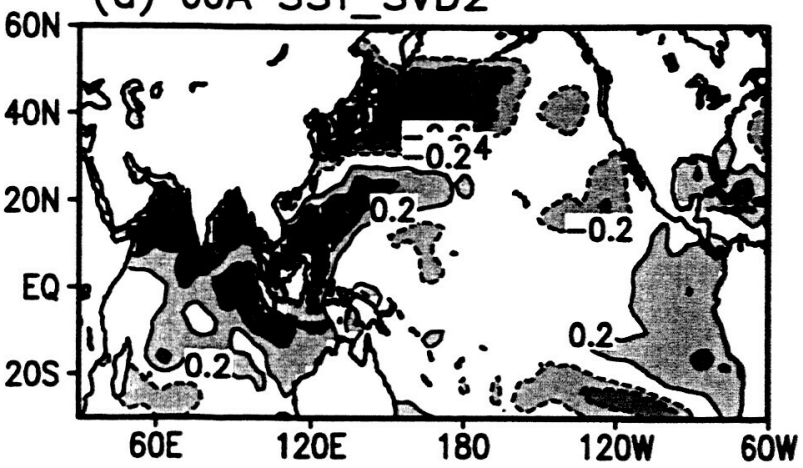

(h) JJA rain_SVD2
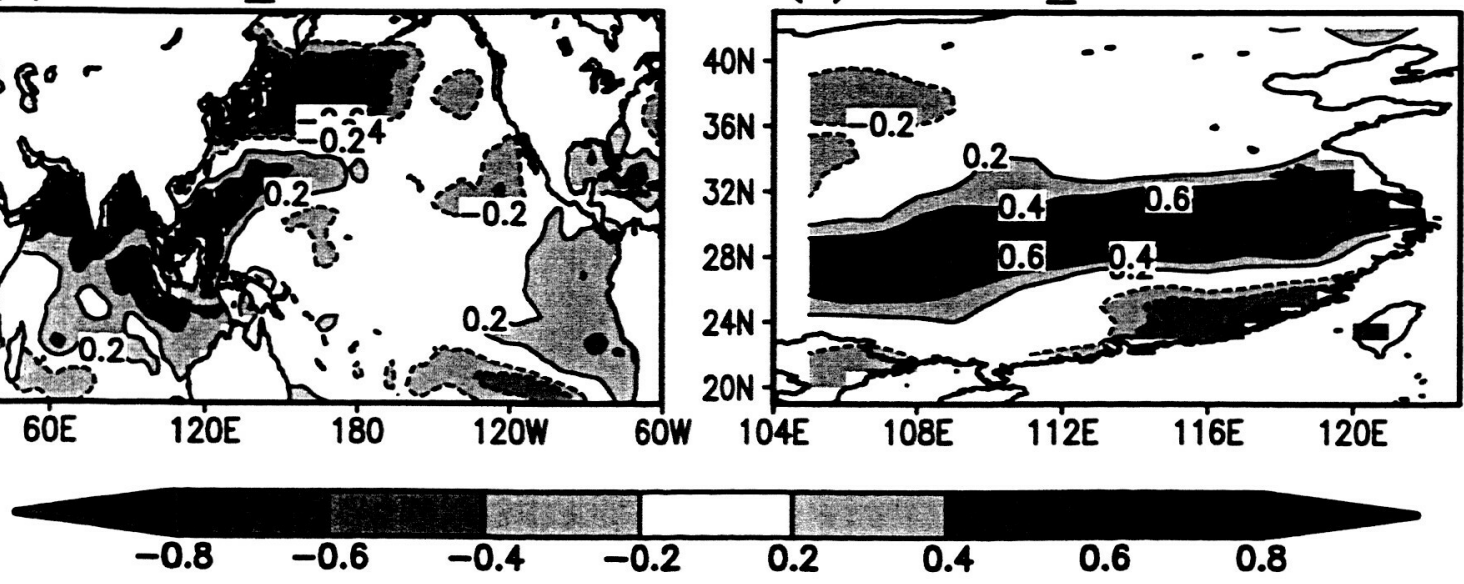
Regression of UV $850 \mathrm{hPa}$ and $\mathrm{Z} 700 \mathrm{hPa}, \mathrm{MAM}$ Based on PC of SVDs, 7-yr high-pass filtered data
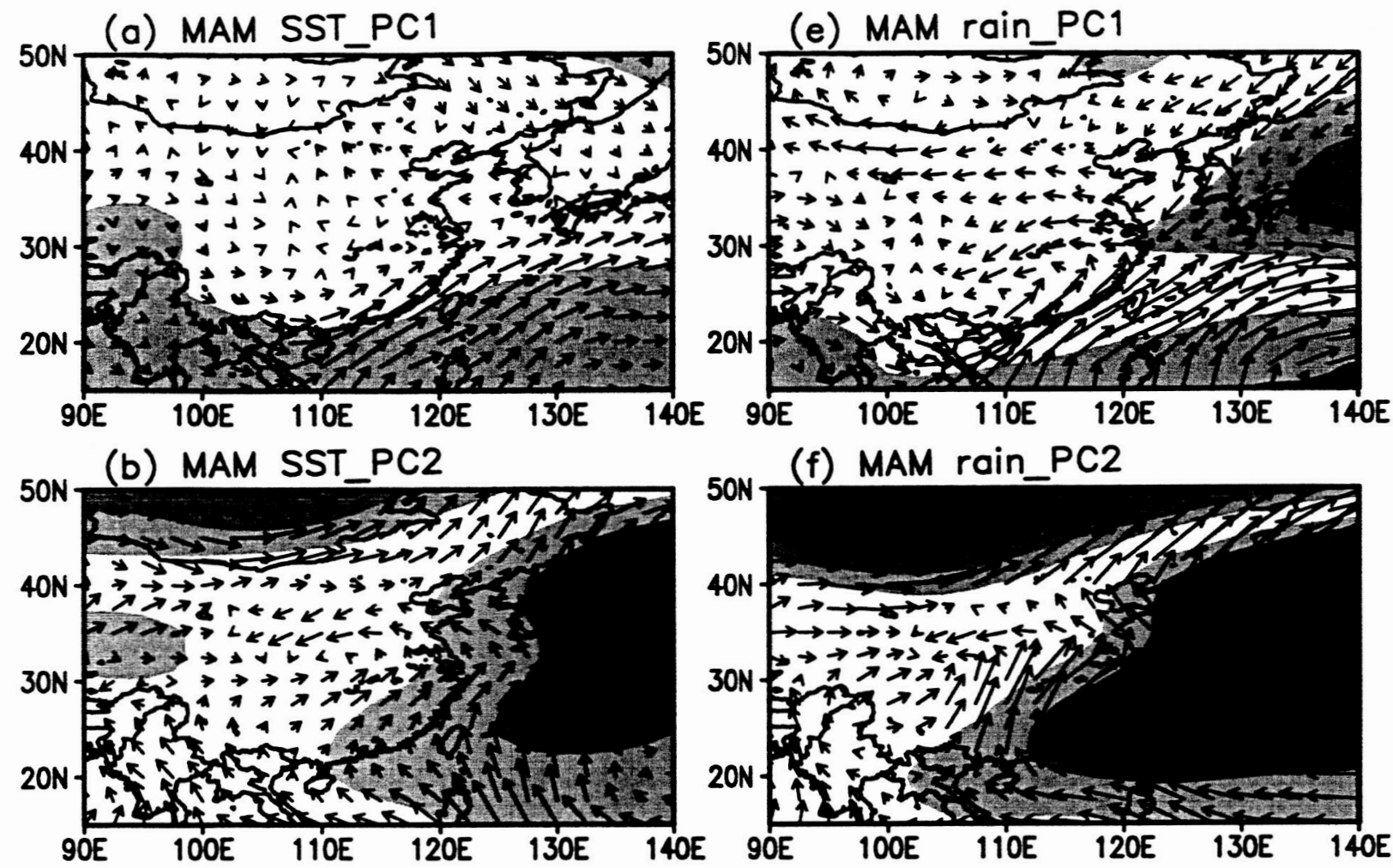

(c) JJA SST_PC1

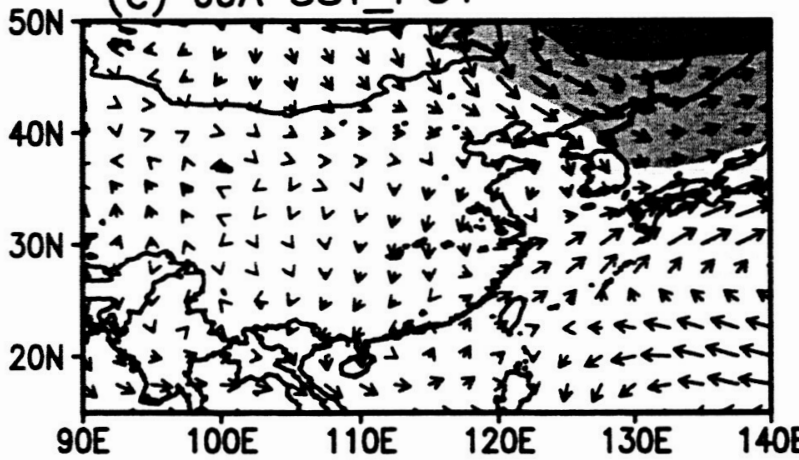

(d) JJA SST_PC2

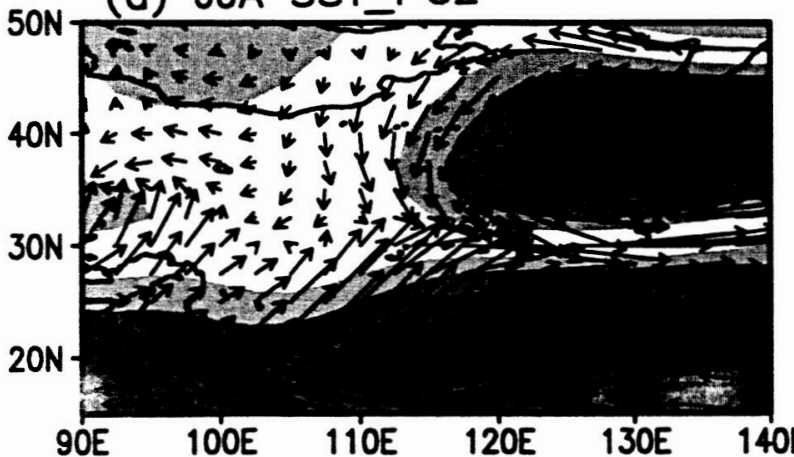

(g) JJA rain_PC1

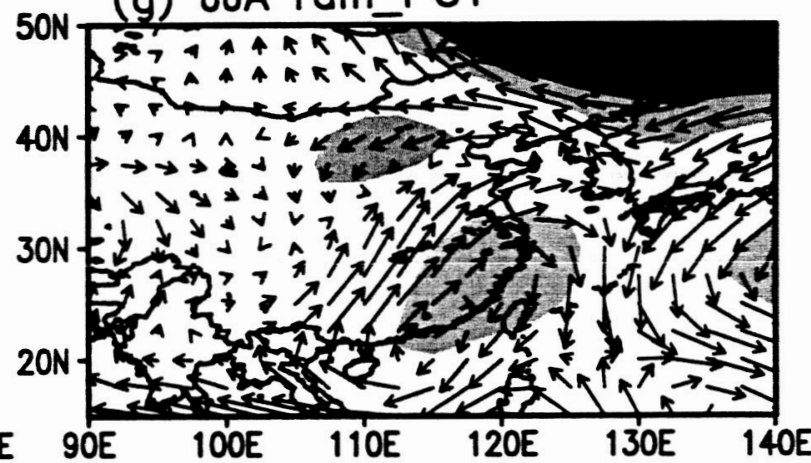

(h) JJA rain_PC2

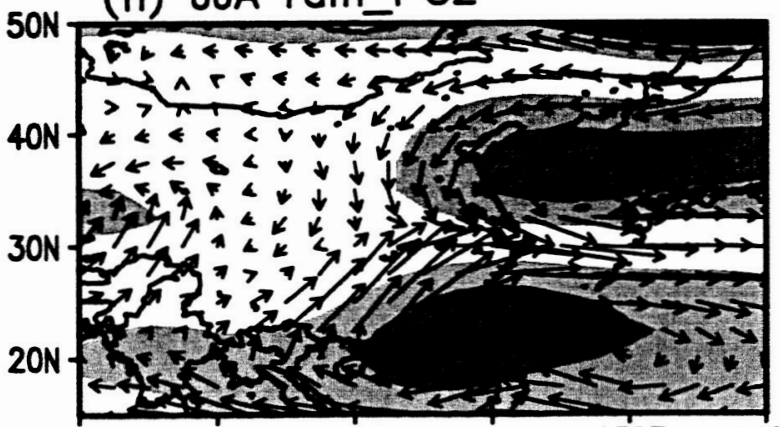

90E 100E 110E 120E I30E I40E

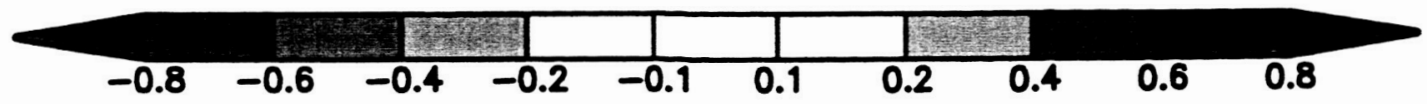


Projects of SST Anomalies to SVD_EOFs of SST

SVD_EOF is from 7-year high-pass filtered data
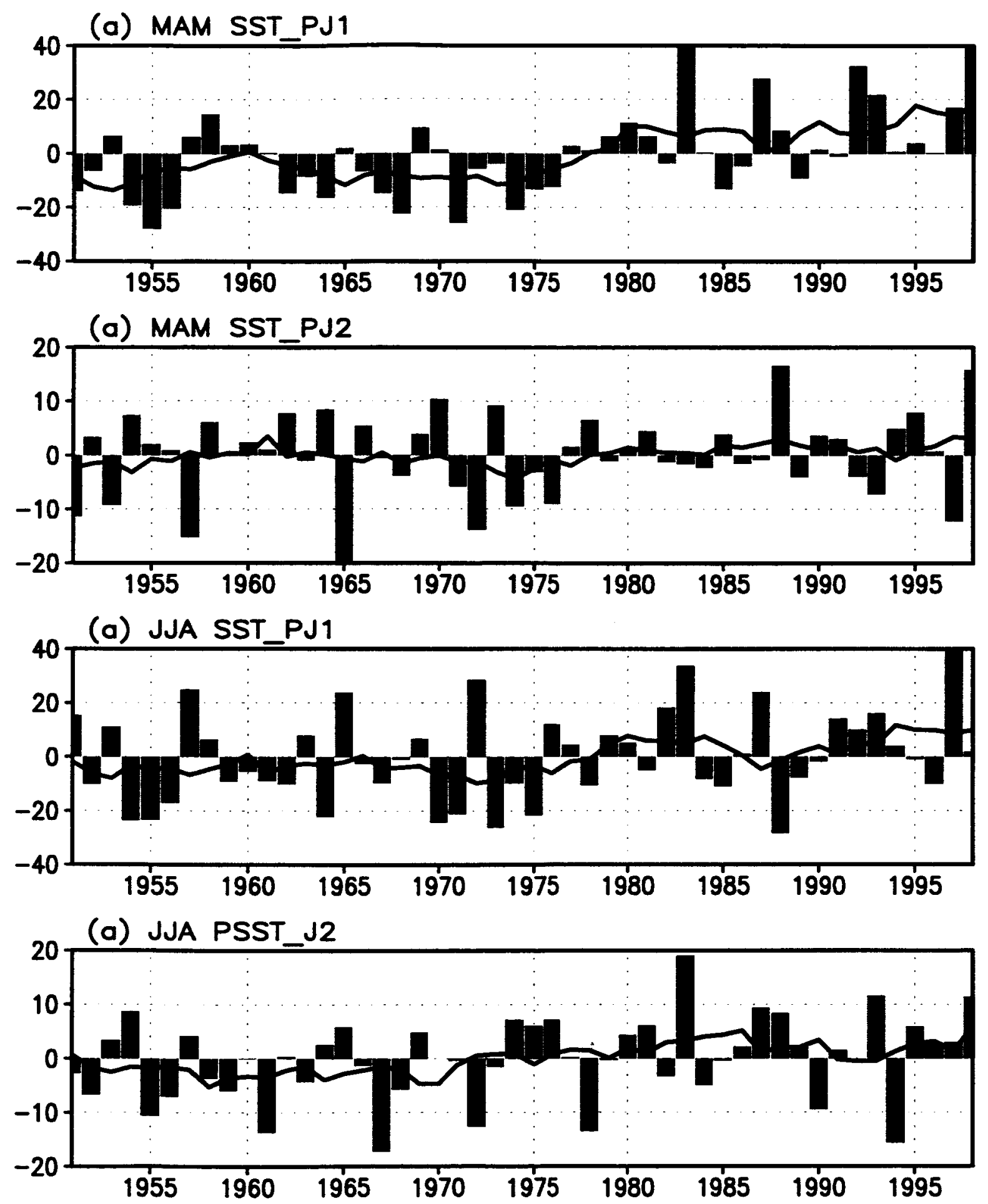
Projects of Rainfall Anomalies to SVD_EOFs of Rainfall SVD_EOF is from 7-year high-pass filtered data

(a) MAM rain_PJ1

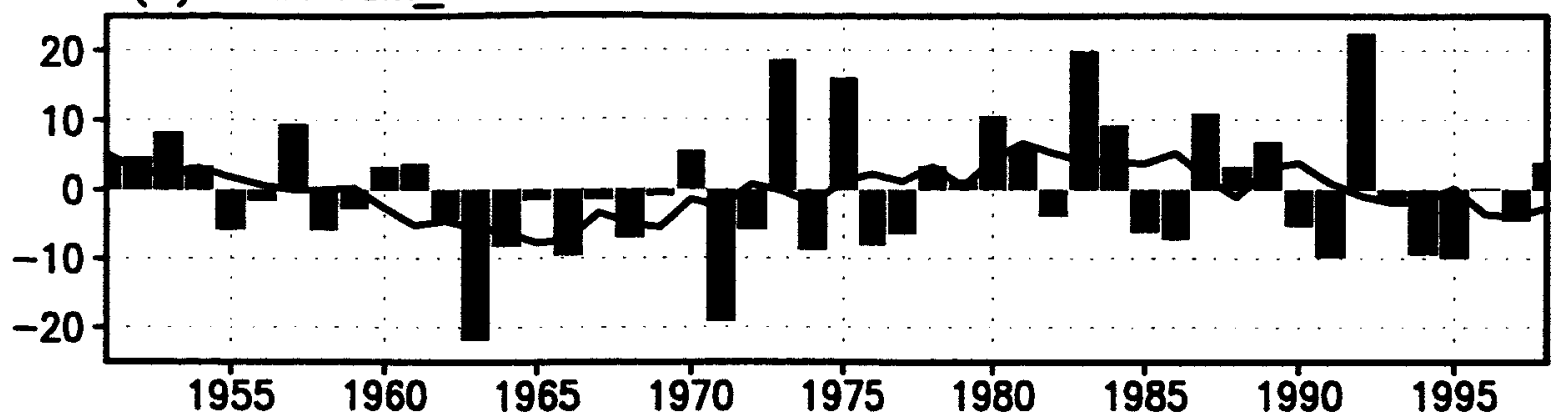

(b) MAM rain_PJ2

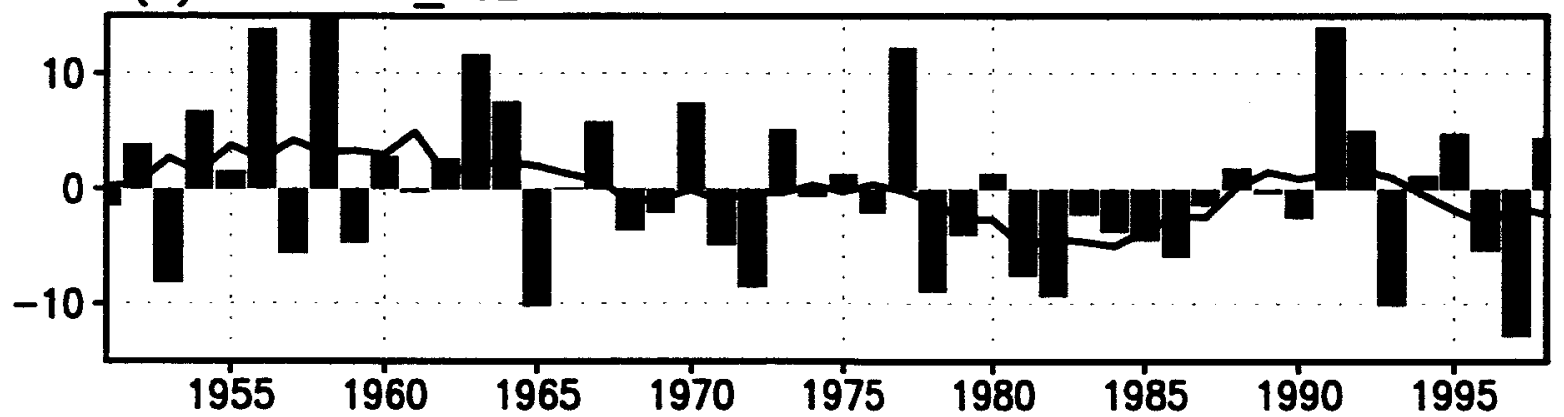

(c) JJA rain_PJ1

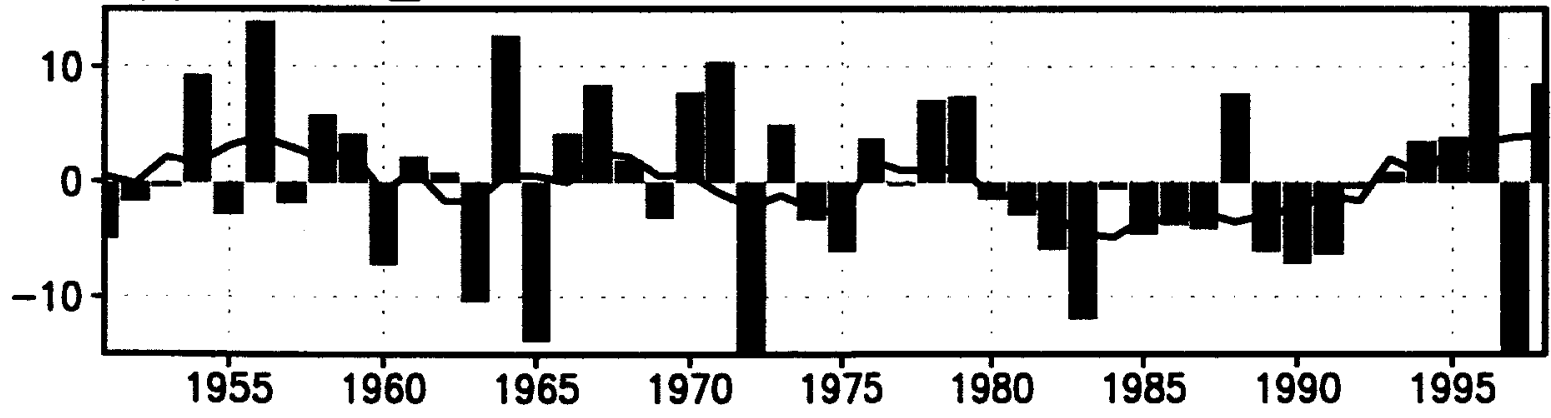

(d) JJA rain_PJ2

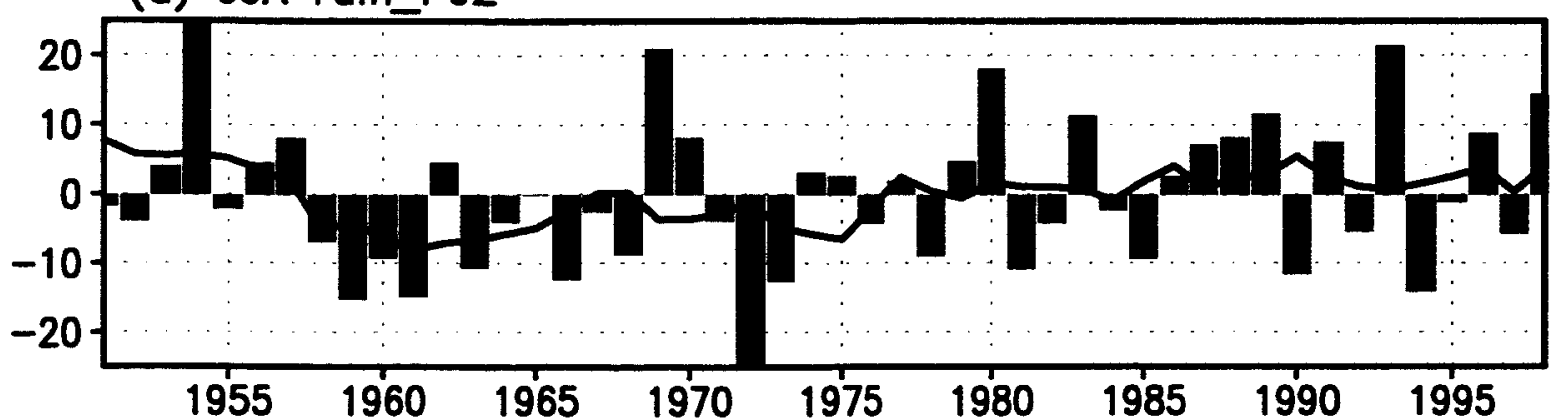


correlation between regional mean rainfall and SST $1951-1998$

(a) MAM, South China, high-pass

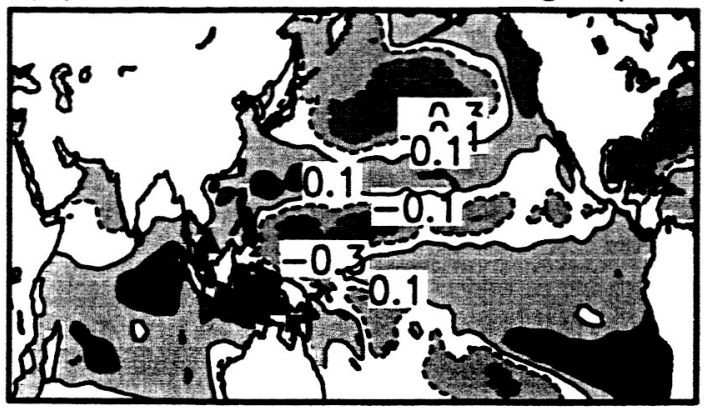

(b) MAM, Central China, high-pass

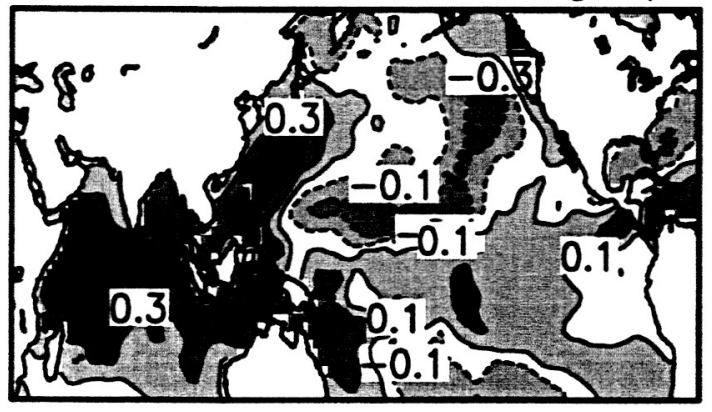

(c) JJA, Central China, high-pass

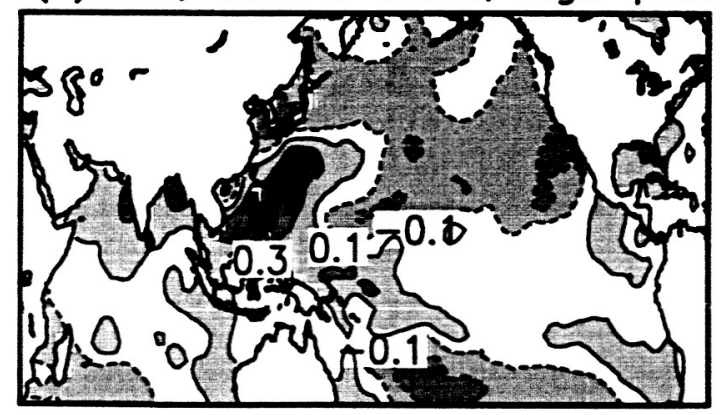

(d) JJA, North China, high-pass

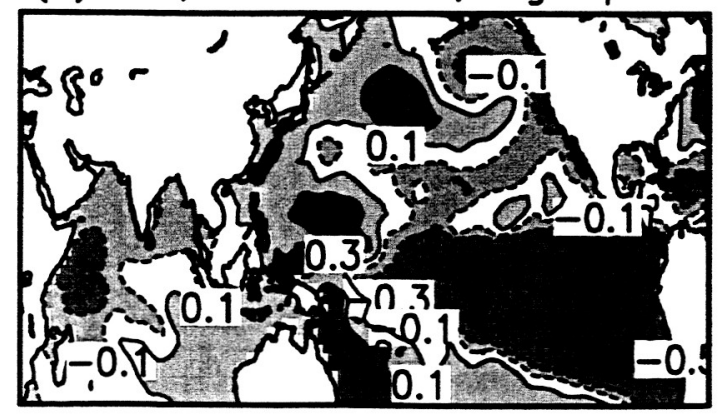

(e) MAM, South China, low-pass

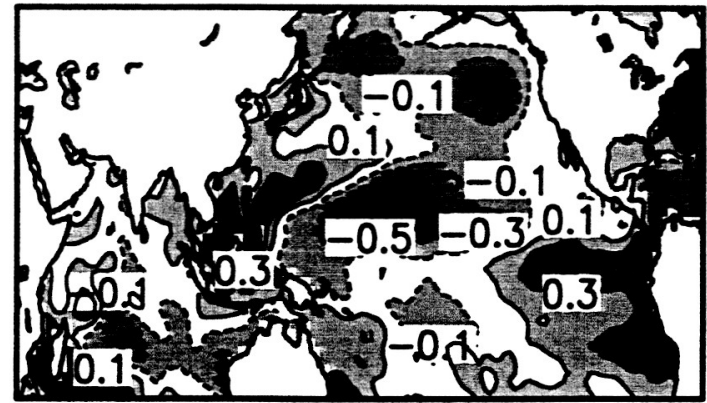

(f) MAM, Central China, low-pass

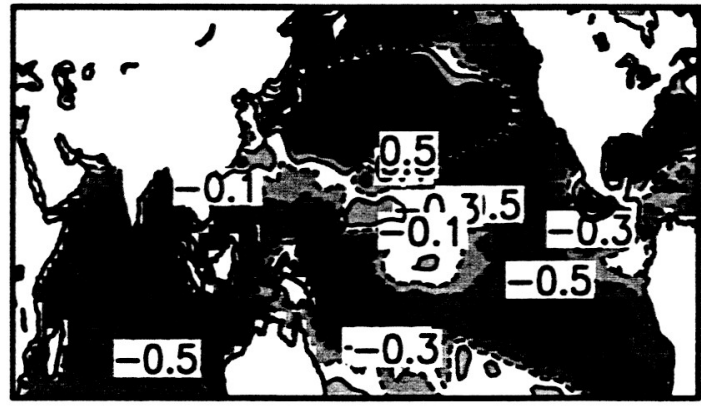

(g) JJA, Central China, low-pass

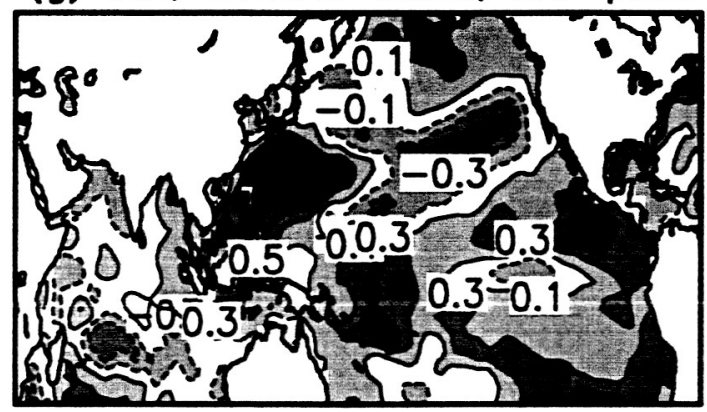

(h) JJA, North China, low-pass

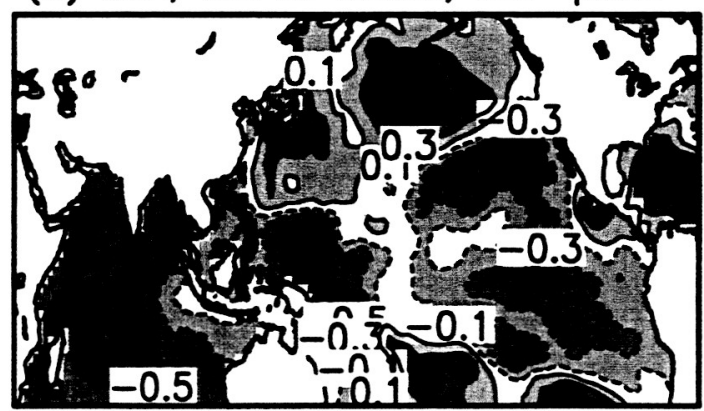

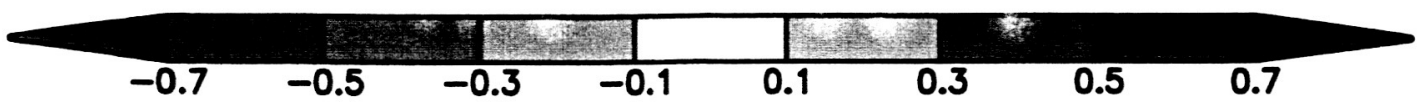


SVD: SST and Rainfall, 1951-98 un-filtered data
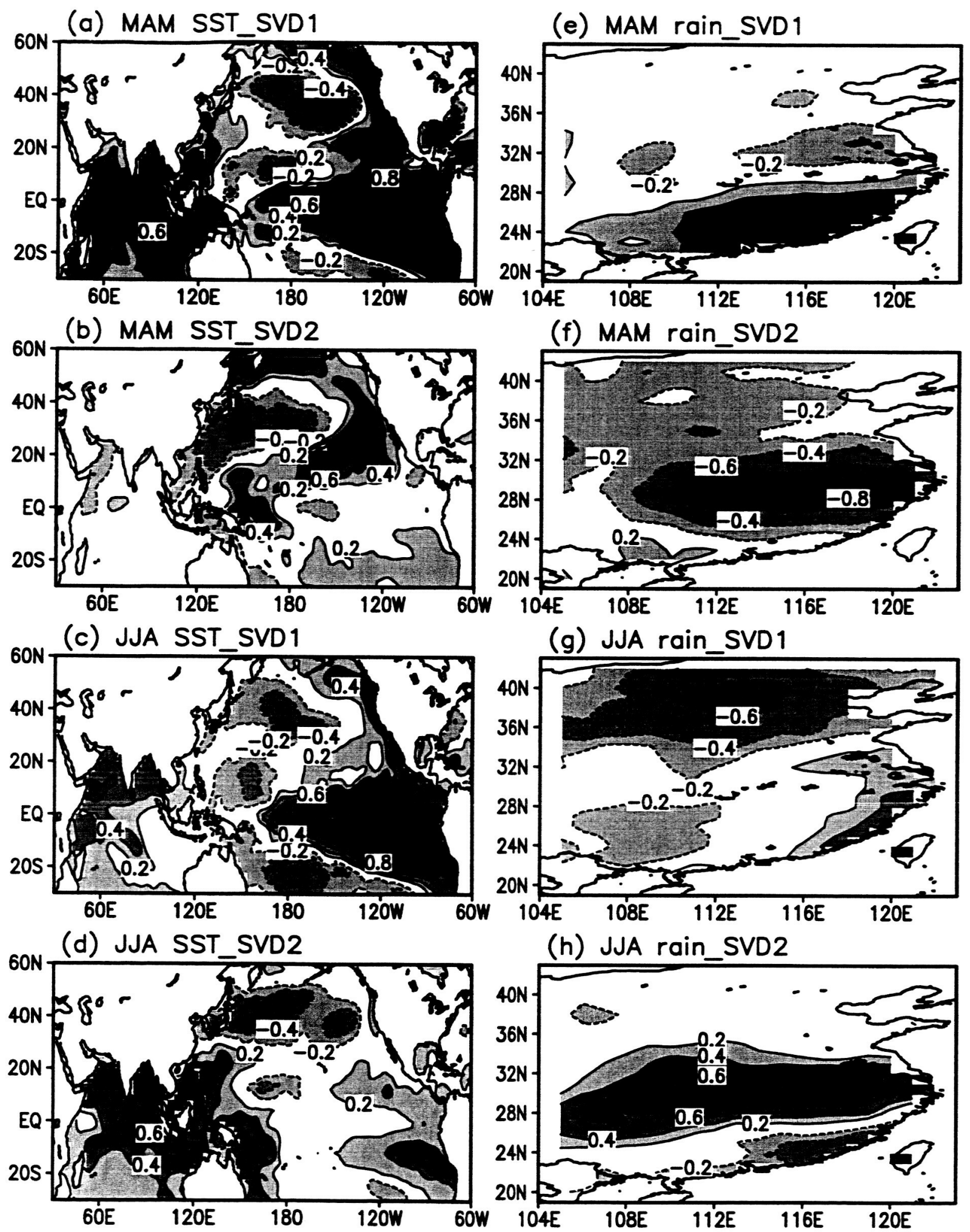

(h) JJA rain_SVD2
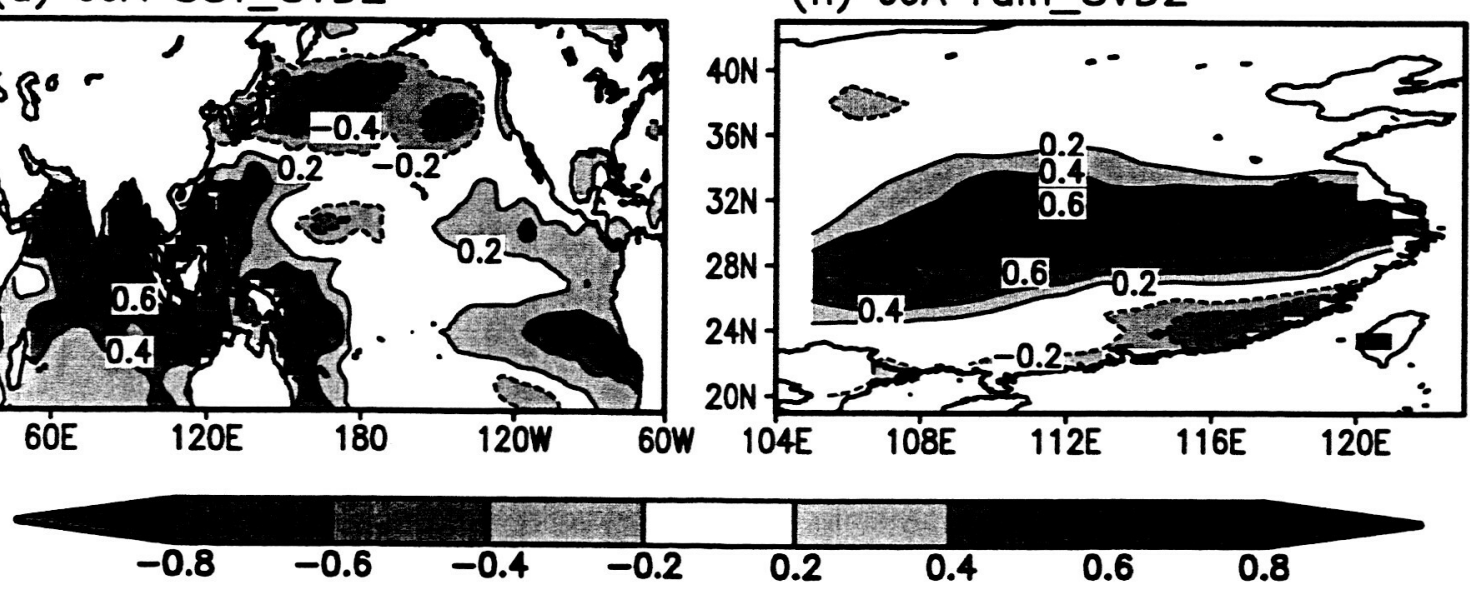
SVD: SST \& Rainfall, Normalized PCs, 1951-1998 un-filtered. Filled Bar: SST; Hollow Bar: Rainfall

(a) MAM, cor[SST_PC1, rain_PC1] $=0.55$

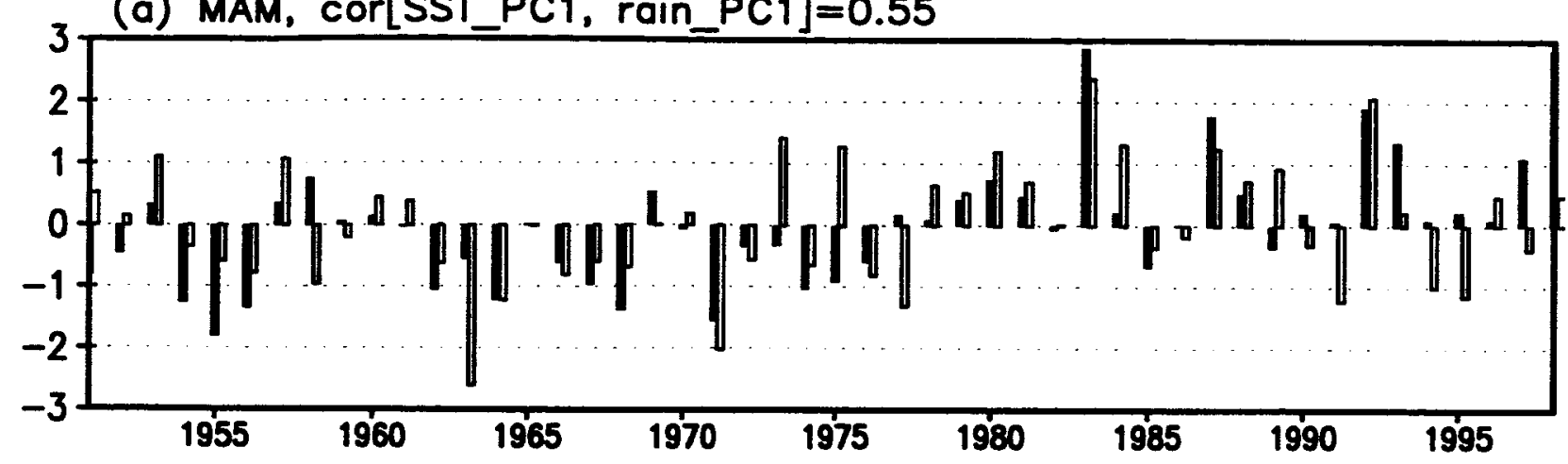

(b) MAM, cor[SST_PC2, rain_PC2] $=-0.61$
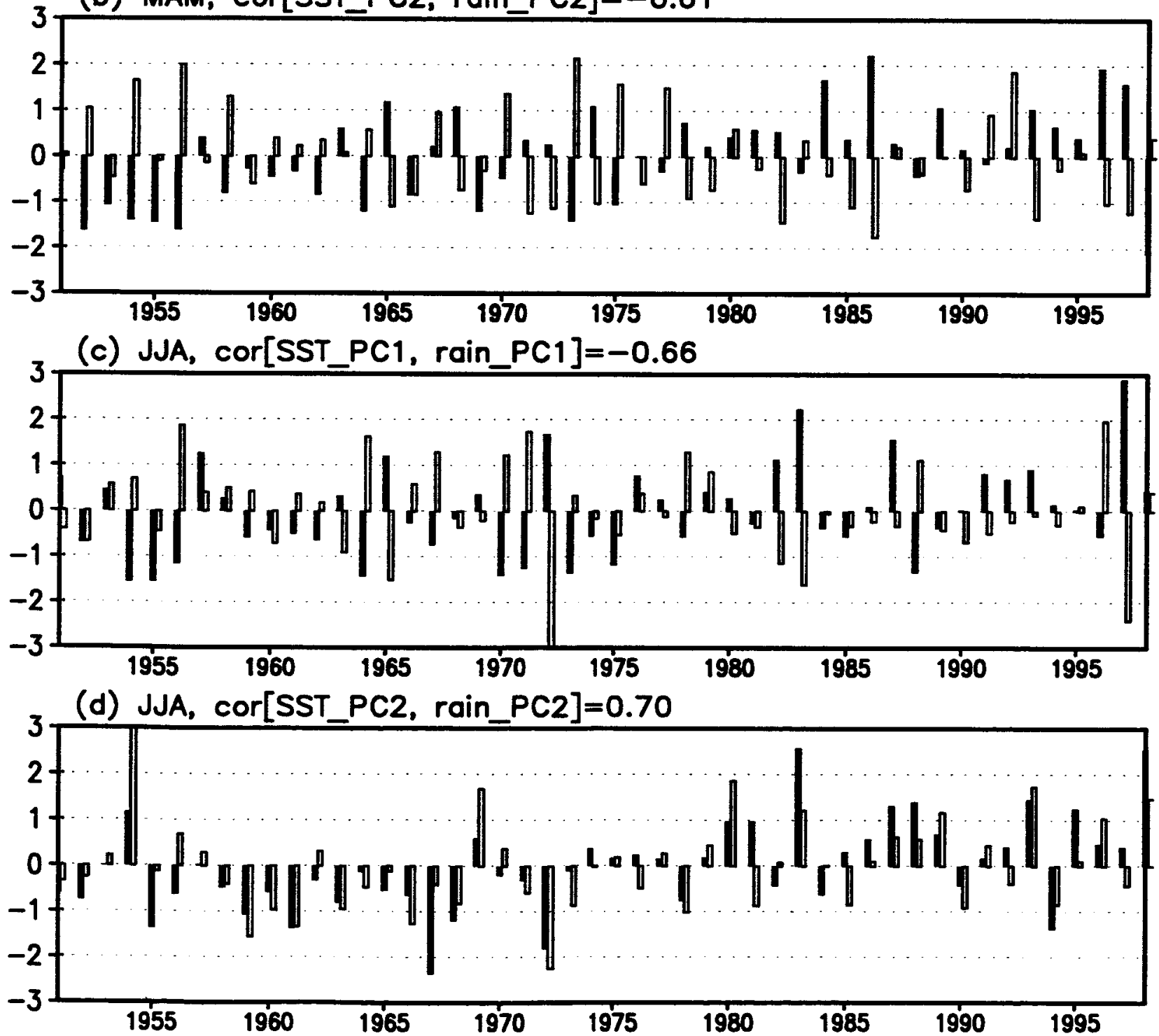